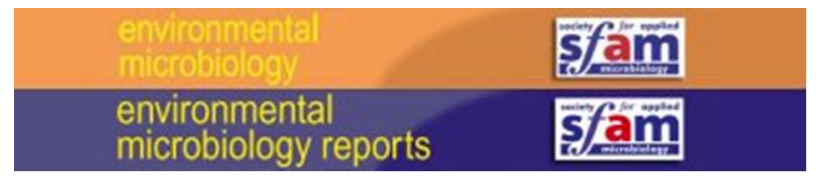

\title{
The LysR-type transcription factor PacR is a global regulator of photosynthetic carbon assimilation in Anabaena
}

\begin{tabular}{|r|l|}
\hline Journal: & Environmental Microbiology and Environmental Microbiology Reports \\
\hline Manuscript ID: & EMI-2014-1511.R1 \\
\hline Manuscript Type: & EMI - Research article \\
\hline Date Submitted by the Author: & Environmental Microbiology \\
\hline Complete List of Authors: & $\begin{array}{l}\text { Picossi, Silvia; Consejo Superior de Investigaciones Científicas, Instituto de } \\
\text { Bioq'uímica Vegetal y Fotosíntesis } \\
\text { Flores, Enrique; Consejo Superior de Investigaciones Científicas, Instituto } \\
\text { de Bioq 'uímica Vegetal y Fotosíntesis } \\
\text { Herrero, Antonia; Consejo Superior de Investigaciones Científicas, Instituto } \\
\text { de Bioquímica Vegetal y Fotosíntesis }\end{array}$ \\
\hline Keywords: & $\begin{array}{l}\text { bacteria, environmental signal/stress responses, gene } \\
\text { expression/regulation }\end{array}$ \\
\hline
\end{tabular}

\section{SCHOLARONE $^{\text {th }}$ \\ Manuscripts}


The LysR-type transcription factor PacR is a global regulator of photosynthetic carbon assimilation in Anabaena

3

4 Silvia Picossi, Enrique Flores and Antonia Herrero*

5

6 Instituto de Bioquímica Vegetal y Fotosíntesis, Consejo Superior de Investigaciones

7 Científicas and Universidad de Sevilla, Américo Vespucio 49, E-41092, Seville, Spain.

10 *Corresponding author. Tel.: +34 954489522. Fax: +34 954460165. E-mail address:

11 herrero@ibvf.csic.es

13 Keywords: ChIP; Cyanobacteria; Oxygenic phototrophy; Photoprotection; RuBisCo

15 Running title: Photosynthetic carbon assimilation regulator

17 Accession link to data:

18 http://www.ncbi.nlm.nih.gov/geo/query/acc.cgi?token=afcxwkacxpydfax\&acc=GSE58861 19 
24 Cyanobacteria perform water-splitting photosynthesis and are important primary producers impacting the carbon and nitrogen cycles at global scale. They fix $\mathrm{CO}_{2}$ through ribulose bisphosphate carboxylase/oxygenase (RuBisCo) and have evolved a distinct $\mathrm{CO}_{2}$ concentrating mechanism $(\mathrm{CCM})$ that builds high $\mathrm{CO}_{2}$ concentrations in the vicinity of RuBisCo favoring its carboxylase activity. Filamentous cyanobacteria such as Anabaena fix $\mathrm{CO}_{2}$ in photosynthetic vegetative cells, which donate photosynthate to heterocysts that rely on a

31 heterotrophic metabolism to fix $\mathrm{N}_{2}$. CCM elements are induced in response to 32 inorganic carbon limitation, a cue that exposes the photosynthetic apparatus to photodamage by over-reduction. An Anabaena mutant lacking the LysR-type transcription factor All3953 grows poorly and dies under high light. The rbcL operon encoding RuBisCo is induced upon carbon limitation in the wild type but not in the mutant. ChIP-Seq analysis was used to globally identify All3953 targets under carbon limitation. Targets include, besides rbcL, genes encoding $\mathrm{CCM}$ elements, photorespiratory pathway, photosystem- and electron transportrelated components, and factors, including flavodiiron proteins, with a demonstrated or putative function in photoprotection. qRT-PCR analysis of

41 selected All3953 targets showed regulation in the wild type but not in the mutant.

42 All3953 (PacR) is a global regulator of carbon assimilation in an oxygenic 43 photoautotroph. 
47 As the organisms that developed oxygenic photosynthesis, cyanobacteria have played

a crucial role in Earth's history and the evolution of life in our planet. Indeed, the production of $\mathrm{O}_{2}$ as a result of cyanobacterial activity was responsible for the oxidation of the Earth's atmosphere about 2.5-2.3 billion years ago (Lyons et al., 2014).

51 Furthermore, all the extant plastids of eukaryotic algae and plants are of cyanobacterial origin. Cyanobacteria were the first organisms to link the activity of the two types of photosystems (PSI and PSII), which allowed the generation of high electrochemical

54 potential, and to combine them with a $\mathrm{H}_{2} \mathrm{O}$-splitting complex. Nowadays, most 55 cyanobacteria are phototrophs relying on oxygenic photosynthesis to generate ATP and reducing equivalents for the fixation of $\mathrm{CO}_{2}$ and the assimilation of inorganic

57 nitrogen. Indeed, they are responsible for an important fraction of the primary productivity in the Earth's oceans, where they are important $\mathrm{CO}_{2}$ and $\mathrm{N}_{2}$ fixers, thus impacting the $\mathrm{C}$ and $\mathrm{N}$ cycles at a global scale (Knoll 2008; Price et al., 2008).

The enzyme responsible for the bulk of $\mathrm{CO}_{2}$ fixation in the biosphere is ribulose-

61 1,5-bisphosphate carboxylase/oxygenase (RuBisCo), which has a relatively low affinity 62 for $\mathrm{CO}_{2}$ and, moreover, it can also accept $\mathrm{O}_{2}$ as a substrate. Compensating for this 63 relatively low performance, RuBisCo is considered the most abundant enzyme on 64 Earth. As a carboxylase, RuBisCo catalyzes the first step of the Calvin-Benson65 Bassham (CBB) cycle, i.e., the incorporation of atmospheric $\mathrm{CO}_{2}$ into ribulose-1,566 bisphosphate to give two molecules of 3-phosphoglycerate. As an oxygenase, it 67 catalyzes the incorporation of $\mathrm{O}_{2}$ into ribulose-bisphosphate, which produces 268 phosphoglycolate that leads to photorespiration with a subsequent loss of fixed $\mathrm{C}$ and 69 energy. To increase the efficiency of $\mathrm{CO}_{2}$ fixation, cyanobacteria have developed a 70 distinct $\mathrm{CO}_{2}$ concentrating mechanism (CCM) constituted by inorganic carbon $\left(\mathrm{C}_{\mathrm{i}}\right)$ 71 transporters that incorporate bicarbonate and $\mathrm{CO}_{2}$ into the cell, and a proteinaceous 72 compartment, the carboxysome, where RuBisCo, together with carbonic anhydrase, is 
73 confined (Price et al., 2008; Cameron et al., 2014). Three high-affinitiy bicarbonate 74 transporters (the $\mathrm{ABC}$-type $\mathrm{Cmp}$, also called $\mathrm{BCT} 1$, and the $\mathrm{Na}^{+}$-dependent BicA and $75 \mathrm{SbtA}$ ), and two $\mathrm{CO}_{2}$ transporters (the high-affinity $\mathrm{NDH}-\mathrm{I}_{3}$ and the low-affinity $\mathrm{NDH}-\mathrm{I}_{4}$ ) 76 have been identified in different cyanobacteria (see Price, 2011). Through CCM, Ci in 77 the form of $\mathrm{CO}_{2}$ can concentrate in the vicinity of cyanobacterial RuBisCo, to allow high specific activity for production of 3-phosphoglycerate to levels much higher than in plants (Cameron et al., 2014). Indeed, components of cyanobacterial CCM have been transformed in tobacco, with the result of improved specific activity of $\mathrm{CO}_{2}$ fixation, which represents a step towards improved photosynthesis in plants (Lin et al., 2014).

In unicellular cyanobacteria, CCM elements are regulated by $\mathrm{C}_{\mathrm{i}}$ availability.

83 Especially genes encoding $C_{i}$ transporters are induced, whereas the structural genes for carboxysome components and the rbcL/S genes encoding RuBisCo are only moderately responsive (see Price et al., 2008; Cameron et al., 2014). In chemotrophic bacteria the process of $\mathrm{CO}_{2}$ fixation and the response to $\mathrm{C}_{\mathrm{i}}$ limitation are usually controlled by LysR-type transcriptional regulators (LTTRs). The genes encoding the enzymes of the CBB cycle are usually found in clusters regulated by CbbR factors, which constitute a sub-family of LTTRs (Gibson and Tabita, 1996). In unicellular cyanobacteria, a number of $\mathrm{CbbR}$ homologs have been characterized. $\mathrm{CmpR}$ is an activator of the cmp genes (Nishimura et al., 2008), whereas CcmR (aka NdhR) acts as a transcriptional repressor of multiple genes encoding other $C_{i}$ transporters (e.g., Figge et al., 2001; Wang et al., 2004). A third type of CbbR-like protein, the activator of the RuBisCo genes, has not yet been identified in cyanobacteria.

Filamentous heterocyst-forming cyanobacteria, of which Anabaena sp. PCC 7120 (hereafter Anabaena) is a model organism, additionally have the capacity for cell differentiation to turn some $\mathrm{O}_{2}$-evolving photosynthetic cells of the filament into heterocysts, which are heterotrophic cells especialized in the fixation of atmospheric $\mathrm{N}_{2}$. Thus, Anabaena is a truly pluricellular bacterium with different cell types specialized in different nutritional tasks that exchange nutrients and regulators and contribute to 
101 the performance of the filament as the organism unit (see Flores and Herrero, 2010).

102 Nitrogen assimilation and heterocyst differentiation in Anabaena are regulated by the 103 global transcription factor NtcA, which responds to the cellular C-to-N ratio, and the 104 heterocyst-specific transcription factor HetR (see Herrero et al., 2013). The Anabaena 105 genomic sequence includes three genes annotated as CbbR-like LTTRs (Kaneko et 106 al., 2001). Of these, all0862 has been identified as $c m p R$, and its product activates the 107 expression of the cmp operon (alr2877-alr2880) and the $c m p R$ gene itself in response 108 to $C_{i}$ limitation (López-lgual et al., 2012). Notably, this regulation is effected in 109 combination with NtcA, thus revealing a mode of co-regulation by $\mathrm{C}$ and $\mathrm{N}$ availability 110 (López-Igual et al., 2012). Furthermore, in Anabaena the rbcLXS operon encoding 111 RuBisCo, which is moderately induced under $C_{i}$ limitation (López-lgual et al., 2012), is 112 repressed in the heterocysts (Madan and Nierzwicki-Bauer, 1993), a regulation likely 113 exerted by NtcA (Ramasubramanian et al., 1994; Picossi et al., 2014).

114 Here we have identified the CbbR-homolog All3953 as the activator of the

115 RuBisCo-encoding operon in Anabaena. We have determined the All3953 regulon by 116 ChIP-Seq, which has revealed that All3953 is a global regulator for $C_{i}$ assimilation 117 genes and genes involved in protection of the photosynthetic apparatus against 118 oxidative damage that are regulated by $\mathrm{Ci}$ availability.

\section{Results}

121 All3953, an RbcR-like factor in Anabaena sp. PCC 7120

122 To gain insight into the LTTR All3953 in Anabaena, the expression of the all3953 gene 123 under different growth conditions was analyzed by northern blot. Three bands of 124 hybridization corresponding to transcripts of ca. $1.9,1.6$ and $1.3 \mathrm{~kb}$, respectively, which 125 appeared similarly represented before and after Ci limitation could be observed (Supp. 126 Fig. 1A). On the other hand, all3953 expression did not significantly respond to $\mathrm{N}$ 127 depletion (Supp. Fig. 1B). The latter result was consistent with previous global 
128 transcriptional studies (Ehira and Ohmori, 2006; Flaherthy et al., 2011) and with the

129 lack of binding associated to all3953 of the $\mathrm{N}$-control transcriptional regulator NtcA 130 upon combined nitrogen depletion (Picossi et al., 2014).

131

132 Isolation and characterization of an all3953 mutant

133 To study the role of All3953, a mutant strain bearing an inactivated version of all3953

134 was constructed (see Experimental procedures). In strain CSS74 most of the all3953

135 gene was deleted and the C.S3 gene cassette (encoding Sm/Sp resistance) was

136 introduced to facilitate segregation and maintenance of the mutation in Anabaena

137 (Supp. Fig. 2A). As a control, strain CSS77 bearing the C.S3 gene cassette in the

138 Anabaena plasmid alpha was also constructed. For cis complementation, a wild-type

139 version of all3953 was transferred to strain CSS74 in an integrative plasmid, 140 generating strain CSS74C (Supp. Fig. 2A).

141 Strain CSS74 exhibited poor growth under standard growth conditions with 142 ammonium as a nitrogen source, and it formed short filaments in liquid medium, 143 whereas strain CSS74C behaved similarly to CSS77 (not shown). To quantify the 144 deleterious effect of the all3953 mutation, growth rates were calculated in liquid 145 medium under different illumination and $\mathrm{C}_{\mathrm{i}}$-supply conditions. Growth rate of the control 146 strain CSS77 was highest $\left(0.892\right.$ days $\left.^{-1}\right)$ under high light $(\mathrm{HL})$ and high carbon (HC), 147 and was about $30 \%$ lower under the other tested conditions (Fig. 1A). In contrast, 148 growth of strain CSS74 was severely affected under HL HC conditions (growth rate ca. $14970 \%$ lower than that of the control) (Fig. 1A), under which it ended up dying after about 1505 days (Fig. 1B). Under HL and low carbon (LC) or low light (LL) HC, the defect was 151 close to $30 \%$ with regard to the control, although after prolonged incubation the mutant 152 was more severely affected under HL LC. The defect was the smallest (ca. 15\%) under 153 LL LC conditions (Fig. 1A,B). In solid medium, growth of strain CSS74 was similar, and 154 similar to that of the control, in the presence of ammonium, nitrate or no combined 
155 nitrogen under LL LC conditions, whereas under HL LC a severe growth defect was 156 observed with regard to the control with any of the tested nitrogen sources (not shown). 157 In summary, the lack of All3953 had a deleterious effect on growth, especially under $158 \mathrm{HL}$ (and $\mathrm{HC})$ conditions.

159 To further characterize the growth defect of the all3953 mutant, the rate of 160 oxygen evolution using $\mathrm{CO}_{2}$ as a final electron acceptor was measured under different 161 illumination conditions in the CSS74 mutant in relation to the control strain CSS77. 162 When exponentially-growing cells were incubated for $24 \mathrm{~h}$ under LL HC, the oxygen 163 evolution rate was slightly lower in strain CSS74 in comparison to CSS77 (88 and $164105 \mu \mathrm{mol} \mathrm{O} \cdot[\mathrm{mg} \mathrm{Chl}]^{-1} \cdot \mathrm{h}^{-1}$, respectively). Under $\mathrm{HL}$ the difference between the two 165 strains was larger (167, for CSS77, and 110 , for CSS74, $\left.\mu \mathrm{mol} \mathrm{O}_{2} \cdot[\mathrm{mg} \mathrm{Chl}]^{-1} \cdot \mathrm{h}^{-1}\right)$.

\section{Effect of all3953 mutation on rbcLXS expression}

To test the effect of the all3953 mutation on the expression of the rbcLXS operon, northern blot analysis was performed with RNA isolated from cells of the control and mutant strains grown with $\mathrm{HC}$ and transferred to $\mathrm{LC}$ conditions. After $1 \mathrm{~h}$ incubation

171 with LC, a ca. 2-fold increase in the amount of the rbcLXS transcripts could be 172 observed in the control strain. No induction could be detected in the mutant (Fig. 2). In 173 the complemented strain CSS74C the expression of $r b c L X S$ increased in LC similarly 174 to the control (Fig. 2). These results indicated that the induction of the rbcLXS operon upon $\mathrm{C}_{\mathrm{i}}$ deficiency was dependent on All3953 and that the defect in strain CSS74 was exclusively due to the lack of All3953.

179 To determine the DNA targets of All3953 at a genomic level, we used chromatin 180 immunoprecipitation followed by high-throughput sequencing analysis. To this end, we 181 constructed a strain (CSS57) expressing from the all3953 promoter a version of 
182 All3953 C-terminally fussed to TAP-tag (Rigaut et al., 1999), as well as a control strain 183 (CSS68) expressing the TAP-tag alone under the control of the all3953 promoter 184 (Supp. Fig. 2B, see Experimental procedures). Immunoprecipitation was carried out using cells of strains CSS57 and CSS68 grown with ammonium as the nitrogen source under $\mathrm{HC}$ conditions and incubated for $3 \mathrm{~h}$ with ammonium under LC conditions.

The analysis of the sequences resulted in a total of 142 All3953 binding regions, of which 127 were located in the chromosome, 10 in plasmid alpha, three in plasmid beta and two in plasmid gamma. Each binding region was ascribed to one or two genes according to the location (midpoint) of the region, and the relative location 191 with respect to the assigned gene was also indicated (Table 1 and Supp. Table 1). A 192 total of 175 genes were ascribed to the 142 binding regions. The binding regions were 193 mostly located upstream of the ascribed genes (72\%), whereas $21 \%$ were intragenic and $7 \%$ were located downstream of genes. The results of the ChIP-Seq analysis are

at

GEO

accession

number

GSE58861

(http://www.ncbi.nlm.nih.gov/geo/query/acc.cgi?acc= GSE58861).

The 175 ascribed genes were classified according to their functional category

(Table 2). Remarkably, there were 19 genes encoding proteins related to photosynthesis and respiration, and 21 genes encoding regulatory proteins, including All7179, a SigB homolog. The rest were mostly genes encoding hypothetical or unknown proteins $(42 \%)$, but also genes encoding proteins involved in translation, in

202 biosynthesis of amino acids and cofactors, prosthetic groups and carriers, in transport, 203 and in other cellular processes. Table 3 highlights All3953-binding regions related to 204 photosynthesis and respiration among which, confirming our results of gene 205 inactivation, the gene encoding the large subunit of the RuBisCo ( $r b c L$; binding region 206 \#37) is included. The fact that a high number of genes involved in photosynthesis and

207 C fixation, including $r b c L$, were identified as targets of RbcR suggests that this protein 208 is a global transcription factor for photosynthetic $\mathrm{C}$ assimilation. 
A CisFinder analysis of the primary consensus motif was carried out based on

210142 high-confidence ChIP-Seq peak sequences (Fig. 3A). The consensus motif found

211 has a dyad-symmetry architecture and matches the consensus of LysR-recognition

212 binding sites (RBS) ( $\left.\mathrm{T}-\mathrm{N}_{11}-\mathrm{A}\right)$ (Maddocks and Oyston, 2008), as well as the consensus

213 binding sites proposed for $\mathrm{CbbR}$ factors (TNA-N $\mathrm{N}_{7 / 8}-\mathrm{TNA}$ ). The primary motifs identified

214 in the central $100 \mathrm{nt}$ of the binding regions are indicated in Supp. Table 1 (for some

215 binding regions more than one motif have been identified).

216

\section{Expression analysis of some All3953 targets in Anabaena}

218 To corroborate our ChIP-Seq analysis and to support the notion that All3953 is indeed

219 a global regulator for $\mathrm{C}$ fixation genes, the expression levels of some of the 220 photosynthesis- and C-fixation-related target genes, its response to $\mathrm{C}_{\mathrm{i}}$ limitation and its dependence on All3953 was further analyzed by qRT-PCR (Fig. 4). Strains CSS77 and

222 CSS74 were grown in ammonium and $\mathrm{HC}$ under standard light conditions (80 $223 \mu \mathrm{E} \cdot \mathrm{m}^{-2} \cdot \mathrm{s}^{-1}$ ) at $30^{\circ} \mathrm{C}$ up to the exponential phase. They were then transferred to medium 224 with ammonium under LC conditions. As previously shown by northern analysis, 225 transcription levels of the all3953 gene did not significantly change after $C_{i}$ deprivation 226 in the control strain CSS77. As expected, al/3953 transcript levels were not detectable 227 in CSS74, corroborating that the all3953 mutation was segregated in this strain. The 228 rbcL gene (alr1524) was 4.6-fold induced at $3 \mathrm{~h}$ after transfer to LC in strain CSS77, 229 whereas no induction was observed in CSS74, thus corroborating the dependence on 230 All3953. Interestingly, under $\mathrm{HC}$ the expression of $r b c L$ in the mutant was higher than 231 in the control strain, suggesting that besides as an activator under LC, All3953 could 232 be acting as a repressor of $r b c L$ under $\mathrm{HC}$ conditions.

233 ORF all4446 (flv4) was highly induced (about 100-fold), and its level was 234 maximum $1 \mathrm{~h}$ after the shift to LC (Fig. 4). In the all3953 mutant, the basal transcription 235 of all4446 in $\mathrm{HC}$ was about 8-fold lower than in the control strain, and it was only 
236 slightly induced (2-fold) upon the shift to LC. all3891 (flv1A) was induced about 6-fold 3

$237 \mathrm{~h}$ after the shift to LC in the control strain, whereas only a 2-fold induction was 238 observed in the all3953 mutant. all1304 (bicarbonate transporter homolog) and alr4156

239 (NdhF homolog) were both highly induced (up to 30- and 20-fold, respectively) upon

240 transfer of strain CSS77 to LC. In contrast, no induction of alr4156 and only a small

241 induction of all1304 took place in strain CSS74. Expression of alr4592 (psbAIII)

242 increased about 5-fold upon $\mathrm{C}_{\mathrm{i}}$ deprivation in CSS77, but did not appreciably change in

243 CSS74. The alr0223 (NdhA homolog) gene was about 2-fold induced under $\mathrm{C}_{\mathrm{i}}$

244 deprivation in CSS77 but not in CSS74. Finally, the expression of alr1004 (alanine-

245 glyoxylate aminotransferase) was repressed by 5 -fold under LC conditions in CSSL77

246 but not in CSS74. These results confirm that expression of the above studied genes is

247 regulated, either positively or negatively, by All3953.

248

\section{Discussion}

250 We have identified the LTTR All3953 as the activator of the RuBisCo-encoding genes 251 in the cyanobacterium Anabaena sp. PCC 7120. All3953 appears to activate the rbcL 252 operon under $C_{i}$ limitation and to repress it when $C_{i}$ is abundant. An LTTR factor 253 regulating the expression of the $r b c L$ operon has not, to our knowledge, been 254 described in any cyanobacterium. The expression of all3953 does not respond to $C_{i}$ 255 limitation (Supp. Fig. 1) and, indeed, no binding region of All3953 was found ascribed 256 to all3953. Thus, the all3953 gene seems to belong to the non-autoregulated LTTRs. 257 All3953 shares 28 and $26 \%$ identical residues with NdhR from Synechocystis sp. PCC 2586803 and Synechococcus sp. PCC 7002 (CcmR), respectively.

259 By ChIP-Seq analysis of a strain bearing a TAP-tagged version of All3953, we 260 have determined 142 All3953-bound regions at $3 \mathrm{~h}$ after transfer from high to low $\mathrm{C}_{\mathrm{i}}$ 261 conditions, which have been assigned to 177 genes. Apart from genes encoding 262 unknown or hypothetical proteins, the larger category is of genes encoding regulatory 
263 proteins, including the transcriptional regulators Alr0353 (a LTTR) and All4500 (CRP-

264 like), the two-component response regulator All3348, the two-component sensor 265 histidine-kinase All1145 and the group 2-sigma 70-type sigma factor All7179 (Supp.

266 Table 1). Interestingly, when comparing to Synechocystis sigma factors, All7179

267 (SigB4) is more similar to SigB, which along with SigD has been shown to be important

268 for PSIl recovery in this unicellular cyanobacterium (Pollari et al., 2009). All3953 also

269 binds upstream of genes patS and het $N$, whose products regulate heterocyst

270 differentiation (Supp. Table 1). The fact that All3953 binds to the promoter region of

271 genes encoding other regulatory proteins suggests a wide role of this protein in the

272 physiology of the organism.

273 In the promoter region of the $r b c L$ operon we have found three putative binding 274 sites for All3953, Box I, Box II, and Box III (Fig. 3B) that resemble the consensus 275 recognition sequence found by Cisfinder analysis (Fig. 3A). It is conceivable that, like in 276 some other LTTRs these boxes combine repression and activation sites. In this regard, 277 binding of All3953 to Box III, overlapping gene promoter elements, could be related to 278 the repression of $r b c L$ observed under high $\mathrm{C}_{\mathrm{i}}$ (Fig. 4). On the other hand, as 279 mentioned above, the rbcL operon is repressed in heterocysts by the global 280 transcriptional regulator $\mathrm{NtcA}$, for which a binding site is found overlapping the operon 281 TSP (Ramasubramanian et al., 1994; Picossi et al., 2014) (Figure 3B). It is conceivable 282 that NtcA binding in these differentiated cells interfere with All3952-mediated activation.

283 Besides being the activator of the RuBisCo genes, All3953 targets include 284 genes involved in other processes related to carbon assimilation, such as $C_{i}$ transport 285 (all1304, encoding an homolog of the BicA bicarbonate transporter; alr4156 encoding a 286 homolog of the NdhF3 subunit of the $\mathrm{NDH}-1_{3} \mathrm{CO}_{2}$ uptake system; and alr0869 287 encoding a homolog of the NdhF4 subunit of the $\mathrm{NDH}-1_{4} \quad \mathrm{CO}_{2}$ uptake system); 288 components of the carboxysome shell (all0868, putative ccmK) and 2289 phosphoglycolate metabolism (alr1004 and alr2873, possibly related to 290 photorespiration [Eisenhut et al., 2008]). Notably, All3953 targets include also a 
291 number of genes encoding photosystem components, such as alr5154 (psaA, 292 encoding the PSI core protein PsaA), alr3727 (psbAll, encoding a component of form II 293 of the PSII core protein PsbA [D1]), alr4592 (psbAIII, encoding another component of 294 form II of PsbA) and alr1216 (PSII $12 \mathrm{kD}$ extrinsic protein PsbU), and genes related to 295 PS activity. In the latter group are alr4149 (biliverdin reductase, putatively involved in 296 phycobilisome -PSII antenna- synthesis), and genes that can participate in 297 photosynthetic electron transfer, such as alr0223 and alr0348 ( $n d h A$ and $n d h D$, 298 subunits of other putative NADH dehydrogenases), alr1576 (dehydrogenase subunit), 299 all0737 (thioredoxin reductase), all1365 (CytM cytochrome), all4148 (ferredoxin I), 300 all3891 and all4446 (flavodiiron proteins Flv1A and Flv4, respectively). (Besides in $\mathrm{CO}_{2}$ 301 uptake, NdhF3 and NdhF4 can also participate in electron transfer.)

302 Reports on gene expression regulation by $C_{i}$ are scarce for Anabaena. 303 However, in the unicellular cyanobacterium Synechocystis sp. PCC 6803 304 transcriptomic analysis has already shown down-regulation of some genes encoding 305 polypeptides of PSI and PSII complexes as well as of phycobilisome components, 306 upon transfer to $\mathrm{C}_{\mathrm{i}}$ limitation conditions, likely as an adaptation to lower assimilatory 307 power demand, and up-regulation of some PSIl core polypeptides, interpreted as 308 adaptation to conditions of shortage of electron acceptors that could lead to 309 photodamage and increased turnover of PS core components (Wang et al., 2004). Our 310 analysis extends the array of photosynthetic genes responding to $C_{i}$ limitation, 311 remarkably to include the core PSI reaction center psaA gene. Moreover, except for 312 alr1004 that responds negatively, all the Anabaena photosynthetic genes mentioned 313 above increase expression upon the shift to $C_{i}$ limitation.

314 Noteworthy, for the majority of photosynthetic gene targets of All3953 in 315 Anabaena, a function in protection against reactive oxygen species, which can be 316 generated by $\mathrm{C}_{\mathrm{i}}$ limitation or exposure to $\mathrm{HL}$, has either been described or could be 317 predicted. Thus, the $p s b A / l$ and $p s b A / l$ genes are induced under $\mathrm{HL}$ in the unicellular 318 Synechococcus sp. PCC 7942, and cells cultured under HL showed more form II, and 
319 less form I (encoded by psbAl), of D1 compared to cells under LL (Schaefer and 320 Golden, 1989). Regarding flavodiiron proteins genes, flv1A, flv3A, and specially flv2 and flv4 of Anabaena have been shown up-regulated in vegetative cells in low $\mathrm{Ci}$, and $f / v 1 A$ and $f / v 3 A$ also in high light, whereas $f / v 1 B$ and $f / v 3 B$ are expressed exclusively in heterocysts (Ermakova et al., 2013). Whereas Flv1A and Flv3A appear involved in photoreduction of oxygen to water by removing excess electrons from PSI through $\mathrm{NAD}(\mathrm{P}) \mathrm{H}$ dehydrogenases, Flv2 and Flv4 could have a role in photoprotection of PSII under low Ci (Ermakova et al., 2013). Regarding photorespiration, it has also been considered to have a role in removal of excess $\mathrm{O}_{2}$ (Eisenhut et al., 2008). To the best of our knowledge, the regulator responsible for the response to $C_{i}$ availability of any photosynthetic gene has not been identified in cyanobacteria (oxygenic phototrophs). Our ChIP-Seq and expression analysis indicate that All3953 is a regulator of photosynthetic genes in Anabaena.

The growth rate of Anabaena is highest under $\mathrm{HL} \mathrm{HC}$ conditions (Fig. 1), 333 implying that this cyanobacterium has mechanisms to get profit of $\mathrm{HC}$ while 334 counteracting HL stress. The all3953 mutant strain CSS74 exhibited a growth defect in 335 all the conditions tested, but especially under HL, where it ends-up dying (Fig. 1). This shares the idea that in Anabaena All3953 is required to cope with HL stress. The effect of the lack of All3953 seems more detrimental in relation to impaired photoprotection

338 than to impaired $C_{i}$ scavenging (preference of the mutant for LL LC over $\mathrm{HL} H C$ 339 conditions). Indeed, even in LL, the mutant seems to perform slightly better with LC 340 than with HC (Fig. 1). Although LC could suppose a limitation of electron acceptors, an 341 increased rate of photorespiration under LC together with the fact that some of the 342 All3953 targets that could cope with excess oxygen are residually induced upon the 343 transfer from $\mathrm{HC}$ to LC in the CSS74 mutant (Fig. 4) could contribute to the preference 344 of this strain for LC over HC, especially under HL.

345 Our results show that in Anabaena the responses to $C_{i}$ availability include 346 regulation of genes encoding elements of $\mathrm{CCM}$ and RuBisCo, but also of 
347 photosynthetic genes to adjust generation of assimilatory power while preserving the

348 photosynthetic apparatus from oxidative damage, which is specially relevant in 349 oxygenic phototrophs. Because All3953 is a transcriptional regulator globally 350 coordinating these responses, we have named it PacR (Photosynthetic assimilation of 351 carbon Regulator).

352

\section{Experimental procedures}

354 Strains

355 Anabaena sp. strain PCC 7120 was grown photoautrophically at $30^{\circ} \mathrm{C}$ with illumination $356\left(80 \mu \mathrm{E} \cdot \mathrm{m}^{-2} \cdot \mathrm{s}^{-1}\right)$ in liquid BG110 medium (Rippka et al., 1979) supplemented with $3 \mathrm{mM}$ $357 \mathrm{NH}_{4} \mathrm{Cl}, 6 \mathrm{mM}$ TES buffer and $10 \mathrm{mM} \mathrm{NaHCO}_{3}$ and bubbled with a mixture of $\mathrm{CO}_{2}$ and 358 air $(1 \% \mathrm{v} / \mathrm{v})(\mathrm{HC})$. Other conditions used were no $\mathrm{NaHCO}_{3}$ supplement and bubbling 359 with air (LC); $12 \mu \mathrm{E} \cdot \mathrm{m}^{-2} \cdot \mathrm{s}^{-1}(\mathrm{LL}) ; 175 \mu \mathrm{E} \cdot \mathrm{m}^{-2} \cdot \mathrm{s}^{-1}(\mathrm{HL})$. For the mutants generated in this 360 work, antibiotics were used at the following concentrations: $\mathrm{Sm}, 2 \mu \mathrm{g} \mathrm{ml}^{-1}$; Sp, $3612 \mathrm{\mu g} \mathrm{ml}^{-1}$; and $\mathrm{Nm}, 25 \mu \mathrm{g} \mathrm{ml}^{-1}$ for bubbled cultures; and Sm, $5 \mathrm{\mu g} \mathrm{ml}^{-1}$; Sp, $5 \mu \mathrm{g} \mathrm{ml}^{-1}$; 362 and $\mathrm{Nm}, 40 \mu \mathrm{g} \mathrm{ml}^{-1}$ for cultures in solid medium.

363

Strain construction

365 To construct a mutant of the all3953 gene, the 5' and 3' end of the gene, along with the 366 flanking regions, were PCR amplified using chromosomal DNA of PCC 7120 as the 367 template and primers all3953-14 (BgllI) and all3953-15 (Sall), and primers all3953-16 368 (Sall) and all3953-17 (Pstl), respectively (all primers are specified in Supp. Table 2).

369 The PCR products were digested with Sall and ligated. The resulting mixture was used 370 as a template for overlapping PCR with primers all3953-14 and all3953-17. The new

371 PCR product was digested with Bglll and Pstl and ligated to the Bglll-Pstl-digested 372 pRL271 (Black et al., 1993), obtaining plasmid pCSS161. Plasmid pCSS161 was 373 digested with Spel and the 2-kb Sm${ }^{r} \mathrm{Sp}^{r}$ gene cassette C.S3, excised with Xbal from 
374 pCSE120 [S.K3/L.HEH2 (BamHI)/C.S3 (BamHI); nomenclature as in (Elhai and Wolk, 375 1988)], was inserted obtaining plasmid pCSS162. Plasmid pCSS162 was transferred to 376 strain PCC 7120 by conjugation (Elhai et al., 1997). Exconjugants resistant to Sm and 377 Sp, which had the $\Delta$ all3953::C.S3 construct integrated by double recombination were 378 selected, obtaining strain CSS74. The segregation of the mutation was tested by PCR 379 (Supp. Fig. 2) with primers all3953-14, all3953-15, all3953-17 and all3953-20. To construct a control strain expressing $\mathrm{Sm}^{r}$ and $\mathrm{Sp}^{r}$ plasmid $\mathrm{pCSS163}$, a derivative of plasmid pCSEL24 (Olmedo-Verd et al., 2006) containing the C.S3 gene cassette, was transferred to Anabaena by conjugation. Exconjugants that had the pCSS163 integrated in the alpha plasmid of Anabaena were selected, obtaining the strain CSS77 (Supp. Fig. 2).

To complement the all3953 mutation of strain CSS74, a DNA fragment encompassing the whole all3953 gene and sequences upstream from it was amplified by PCR using the primer pair all3953-24/all3953-25, both including EcoRI sites, and strain PCC 7120 DNA as the template. This fragment was cloned in the EcoRI site of the mobilizable $\mathrm{Nm}^{\mathrm{r}}$ encoding vector pRL424 (Elhai and Wolk, 1988) producing plasmid pCSS164, which was transferred to strain CSS74 by conjugation followed by selection for $\mathrm{Nm}^{\mathrm{r}}$. The genomic structure of the exconjugants in the all3953 region (Supp. Fig. 2) was corroborated by PCR.

To construct a strain expressing All3953-C-TAP, the all3953 gene (including the upstream region) was PCR-amplified with primers all3953-11 and all3953-12 and DNA of PCC 7120 as the template. The TAP-tag was PCR-amplified with primers TAPtag-1 and TAPtag-2 using DNA of plasmid pBS1479 as the template (Puig et al., 2001). The two PCR products were digested with Sall and ligated, after which the ligation product

398 was used as the template for an overlapping PCR using primers all3953-11 and

399 TAPtag-2. The PCR product was digested with Pstl and ligated to the mobilizable 400 vector pCSV3 (Valladares et al., 2011) digested with Pstl, rendering plasmid pCSS107. 

promoter, a $0.4-\mathrm{kb}$ region upstream of all3953 was PCR-amplified using primers all3953-11 and all3953-18 and DNA of pCSS107 as the template. The PCR product was digested with Sall and ligated to the PCR-amplified TAP-tag digested with Sall, after which the ligation product was used as the template for an overlapping PCR using primers all3953-11 and TAPtag-2. The PCR product was digested with Pstl and ligated to Pstl-digested pCSV3 to give plasmid pCSS157. Plasmids pCSS107 and pCSS157 were transferred by conjugation to strain PCC 7120 and single $\mathrm{Sm}^{r} \mathrm{Sp}^{r}$ recombinants were selected, obtaining strain CSS57 and CSS68, respectively. Western blots using

410 Peroxidase-Anti-Peroxidase Soluble Complex (PAP, Sigma-Aldrich) were performed to ensure that the two strains expressed the TAP-tag (Supp. Fig. 2B).

\section{Chromatin immunoprecipitation}

414 Cells of strains CSS57 growing exponentially (3-5 $\left.\mu \mathrm{g} \mathrm{Chl} \cdot \mathrm{ml}^{-1}\right)$ in the light (80 $\left.415 \mu \mathrm{E} \cdot \mathrm{m}^{-2} \cdot \mathrm{s}^{-1}\right)$ in medium supplemented with $2 \mu \mathrm{g} \cdot \mathrm{ml}^{-1} \mathrm{Sm}$ and $\mathrm{Sp}$, in $\mathrm{HC}$ conditions were 416 incubated with LC for $3 \mathrm{~h}$. Formaldehyde was then added to the cultures to a final 417 concentration of $1 \%$, and the cultures were incubated for $15 \mathrm{~min}$. Glycine was added at $418125 \mathrm{mM}$ final concentration and the incubation was continued for $5 \mathrm{~min}$ to stop the 419 fixing reaction. The cells were then filtered, washed with cold TBS $(20 \mathrm{mM}$ Tris- $\mathrm{HCl}, \mathrm{pH}$ $4207.4,140 \mathrm{mM} \mathrm{NaCl}$ ) and collected in tubes (25 $\mathrm{ml}$ of culture per tube). The pellets were 421 frozen in liquid nitrogen and stored at $-20^{\circ} \mathrm{C}$ until used. Pellets corresponding to about $42225 \mathrm{ml}$ of culture were resuspended in $500 \mu \mathrm{l}$ of lysis buffer $(50 \mathrm{mM} \mathrm{HEPES}-\mathrm{KOH}, \mathrm{pH}$ $4237.5,140 \mathrm{mM} \mathrm{NaCl}, 1 \mathrm{mM}$ EDTA, 1\% Triton X-100, 0.1\% sodium deoxycholate, 424 supplemented with Mini EDTA-free protease inhibitor cocktail [Roche]) and, after 425 addition of $150 \mu$ of glass beads (acid-washed, 425-600 $\mu \mathrm{m}$ [Sigma]), the cells were 426 broken in a multivortexer at $2,000 \mathrm{rpm}$ for $1 \mathrm{~h}$ at $4^{\circ} \mathrm{C}$. The cell lysates were collected by 427 centrifugation and the extracts were subjected to sonication to shear the DNA to about $428300-b p$ fragments (60 cycles of 10 s, 20 s ice, $15 \%$ amplitude, in a Branson Digital 
429 Sonifier). After centrifugation to eliminate cell debris, the whole-cell extracts were 430 stored at $-20^{\circ} \mathrm{C}$ or immediately used for immunoprecipitation.

431 Immunoprecipitation of DNA was carried out as described (Picossi et al., 2014),

432 with some modifications. Whole-cell extracts were prepared at $4 \mathrm{mg} \cdot \mathrm{ml}^{-1}$ of total protein 433 with lysis buffer (in $500 \mu \mathrm{l}$ total volume). A $50-\mu \mathrm{l}$ sample was taken as the input sample, 434 and the extracts were incubated with $15 \mu \mathrm{lgG}$-conjugated Dynabeads (about $6 \mu \mathrm{g}$ $435 \operatorname{lgG})$ at $4^{\circ} \mathrm{C}$ with rotation for $12-14 \mathrm{~h}$. The washes of the Dynabeads, as well as the 436 elution of the immunoprecipitated material, the crosslinking reversion and the isolation 437 of the DNA were performed as in (Picossi et al., 2014).

438

Massive sequencing of the immunoprecipitated DNA

440 Input and ChIP DNA samples were sent for sequencing to the Functional Genomics 441 Core Facility of the Institute for Research in Biomedicine, Barcelona (Spain). Next 442 generation sequencing was carried out using Illumina's sequencing technology. ChIP 443 DNA Sample Prep Kit (Illumina) was used for library preparation. Libraries were loaded 444 at $8 \mathrm{pM}$ concentration into the flow cell using the Cluster Station running recipe V7 with 445 the Single-Read Cluster Generation Kit v4 (all Illumina). The flow cell was loaded into 446 the Genome Analyzer II and samples were sequenced for 120 nucleotides from a 447 single end using the Sequencing Kit v5 and recipe v8 (all Illumina). Manufacturer's 448 recommendations were strictly followed. Illumina sequencing data were pre-processed 449 with the standard Illumina pipeline version 1.5 and sequences were aligned to the PCC 4507120 genome (http://genome.microbedb.jp/cyanobase/Anabaena) with the Bowtie 451 software 0.12 .5 (Langmead et al., 2009). The analysis of the results were carried out 452 using the Triform algorithm (Kornacker et al., 2012) as in (Picossi et al., 2014). The 453 sequences in the ChIP samples of strain CSS68 (TAP control) were used as the 454 background of the sequences found for strain CSS57 (All3953-TAP), and thus to 455 determine the specific binding regions of All3953-TAP in the genome of Anabaena. 
456 The binding regions were visualized and analyzed using the UCSC Microbial Genome

457 Browser (Scheneider et al., 2006). They were ascribed to one or two genes, in case it 458 was not possible to ascribe them to only one, and classified as upstream of the gene, if

459 the midpoint of the binding region was located upstream of the start of the gene, 460 internal, if the midpoint of the binding region was inside the gene, or downstream, if the 461 midpoint of the binding region was located downstream of the end of the gene to which 462 it had been ascribed.

463

Northern and qRT-PCR analyses

465 Isolation of total RNA from Anabaena was done as described previously (Mohamed 466 and Jansson, 1989). Northern analysis was performed as described previously (López467 Igual et al., 2012).

468 For qRT-PCR, $750 \mathrm{ng}$ of DNA-free RNA samples were used for all the PCR 469 primer pairs. For the RT reaction, the Quantitech Reverse transcription kit (Qiagen), 470 with the Random Hexamer Primer mix (100 ng per sample) (Bioline) was used. The 471 cDNA produced was diluted 7.5 times to use $2 \mu \mathrm{l}$ of CDNA per PCR reaction. PCR was 472 done using the Quantimix Easy SYG Kit (Biotools) (SYBR green I) in a iCycler iQ Multi473 Color Real Time PCR Detection System (Bio-Rad). The abundance of a transcript in 474 the RNA sample was calculated as: abundance $=2^{\wedge}[\mathrm{Ct}($ sample $)-\mathrm{Ct}($ control $)]$, where the 475 RNA sample of the control strain CSS77 in HC condition (0) was used as the control.

\section{Oxygen evolution}

478 2-ml samples of exponentially grown cultures in $\mathrm{HC}$ LL or HC HL conditions were used 479 to measure $\mathrm{O}_{2}$ evolution with an $\mathrm{O}_{2}$ electrode calibrated with culture medium and $480 \mathrm{Na}_{2} \mathrm{~S}_{2} \mathrm{O}_{4}$ as the reducing agent. $\mathrm{O}_{2}$ production was measured in the light (400 $481 \mu \mathrm{E} \cdot \mathrm{m}^{-2} \cdot \mathrm{s}^{-1}$ ) after a seven-minute incubation in the dark. 
484 This work was supported by grants BFU2010-17980 and BFU2013-44686-P from the

Spanish government, co-financed by FEDER. The authors are grateful to K. Kornacker

for carrying out the Triform and CisFinder analyses, and to H. Auer and I. Pons, from

487 the Functional Genomics Core Facility of the IRB, Barcelona (Spain); to F. Monje-

488 Casas and Yagut Allahverdiyeva-Rinne for critical reading of the manuscript and to $\mathrm{M}$.

489 J. Huertas and A. Torrado for help with $\mathrm{O}_{2}$ production measurements.

490

491

492

493

494

495

496

497

498

499

500

501

502

503

504

505

506

507

508

509

510

511

512

513

514

515

516

517

518

519

520

521

522

523

524

525

526

527

528

\section{REFERENCES}

Black, T.A., Cai, Y., and Wolk C.P. (1993) Spatial expression and autoregulation of $h e t R$, a gene involved in the control of heterocyst development in Anabaena. Mol Microbiol 9: 77-84.

Cameron, C.J., Sutter, M., and Kerfeld, C.A. (2014) The carboxysome: Function, structure and cellular dynamics. The Cell Biology of Cyanobacteria, eds. Flores E, Herrero A (Caister Academic Press, Norfolk), pp. 171-188.

Ehira, S., and Ohmori, M, (2006) NrrA, a nitrogen-responsive response regulator facilitates heterocyst development in the cyanobacterium Anabaena sp. strain PCC 7120. Mol Microbiol 59: 1692-1703.

Elhai., J., Vepritskiy, A., Muro-Pastor, A.M., Flores, E, and Wolk, C.P. (1997) Reduction of conjugal transfer efficiency by three restriction activities of Anabaena sp. strain PCC 7120. J Bacteriol 179: 1998-2005.

Eisenhut, M., Ruth, W., Haimovich, M., Bauwe, H., Kaplan, A., and Hagemann, M. (2008) The photorespiratory glycolate metabolism is essential for cyanobacteria and might have been conveyed endosymbiotically to plants. Proc Natl Acad Sci USA 105: $17199-17204$.

Elhai, J., and Wolk, C.P. (1988) A versatile class of positive-selection vectors based on the nonviability of palindrome-containing plasmids that allows cloning into long polylinkers. Gene 68: 119-138.

Ermakova, M., Battchikova, N., Allahverdiyeva, Y., and Aro, E.M. (2013) Novel heterocyst-specific flavodiiron proteins in Anabaena sp. PCC 7120. FEBS Lett 587: 82-7.

Figge, R.M., Cassier-Chauvat, C., Chauvat, F., and Cerff, R. (2001) Characterization and analysis of an $\mathrm{NAD}(\mathrm{P}) \mathrm{H}$ dehydrogenase transcriptional regulator critical for the survival of cyanobacteria facing inorganic carbon starvation and osmotic stress. Mol Microbiol 39: 455-68.

Flaherty, B.L., Van Nieuwerburgh, F., Head, S.R., and Golden, J.W. (2011) Directional RNA deep sequencing sheds new light on the transcriptional response of Anabaena sp. strain PCC 7120 to combined-nitrogen deprivation. BMC Genomics 12: 332.

Flores, E., and Herrero, A. (2010) Compartmentalized function through cell differentiation in filamentous cyanobacteria. Nat Rev Microbiol 8: 39-50.

Gibson, J.L., and Tabita, F.R. (1996) The molecular regulation of the pentose phosphate pathway in proteobacteria and cyanobacteria. Arch Microbiol 166: 141150.

Herrero, A., Picossi, S., and Flores, E. (2013) Gene Expression during heterocyst differentiation. Adv Bot Res 65: 281-329. 
Kaneko, T., Nakamura, Y., Wolk, C.P., Kuritz, T., Sasamoto, S., and Watanabe, A. (2001) Complete genomic sequence of the filamentous nitrogen-fixing cyanobacterium Anabaena sp. strain PCC 7120. DNA Res 8: 205-213.

Knoll, A.H. (2008) Cyanobacteria and Earth history. The Cyanobacteria: Molecular Biology, Genomics and Evolution, eds. Herrero A, Flores E (Caister Academic Press, Norfolk), pp. 1-19.

Kornacker, K., Rye, M.B., Handstad, T., and Drablos, F. (2012) The Triform algorithm: improved sensitivity and specificity in ChIP-Seq peak finding. BMC Bioinformatics 13: 176.

Langmead, B., Trapnell, C., Pop, M., and Salzberg, S.L. (2009) Ultrafast and memoryefficient alignment of short DNA sequences to the human genome. Genome Biol 10: R25.

Lin, M.T., Occhialini, A., Andralojc, P.J., Parry, M.A.J., and Hanson, M.R. (2014) A faster Rubisco with potential to increase photosynthesis in crops. Nature 513: 547550.

López-Igual, R., Picossi, S., López-Garrido, J., Flores, E., and Herrero, A. (2012) N and $\mathrm{C}$ control of ABC-type bicarbonate transporter $\mathrm{Cmp}$ and its LysR-type transcriptional regulator $\mathrm{CmpR}$ in a heterocyst-forming cyanobacterium, Anabaena sp. Environ Microbiol 14: 1035-1048.

Lyons, T.W., Reinhard, C.T., and Planavsky, N.J. (2014) The rise of oxygen in Earth's early ocean and atmosphere. Nature 506: 307-315.

Madan, A.P., and Nierzwicki-Bauer, S.A. (1993) In situ detection of transcripts for ribulose-1,5-bisphosphate carboxylase in cyanobacterial heterocysts. J Bacteriol 175: 7301-7306.

Maddocks, S.E., and Oyston, P.C. (2008) Structure and function of the LysR-type transcriptional regulator (LTTR) family proteins. Microbiology 154: 3609-3623.

Mohamed, A., and Jansson, C. (1989) Influence of light on accumulation of photosynthesis-specific transcripts in the cyanobacterium Synechocystis 6803. Plant Mol Biol 13: 693-700.

Nierzwicki-Bauer, S.A., Curtis, S.E., and Haselkorn, R. (1984) Cotranscription of genes encoding the small and large subunits of ribulose-1,5-bisphosphate carboxylase in the cyanobacterium Anabaena 7120. Proc Natl Acad Sci USA 81: 5961-5965.

Nishimura, T., Takahashi, Y., Yamaguchi, O., Suzuki, H., Maeda, S., and Omata, T. (2008) Mechanism of low $\mathrm{CO}_{2}$-induced activation of the $\mathrm{cmp}$ bicarbonate transporter operon by a LysR family protein in the cyanobacterium Synechococcus elongatus strain PCC 7942. Mol Microbiol 68: 98-109.

Olmedo-Verd, E., Muro-Pastor, A.M., Flores, E., and Herrero, A. (2006) Localized induction of the $n t c A$ regulatory gene in developing heterocysts of Anabaena sp. strain PCC 7120. J Bacteriol 188: 6694-6649.

Picossi, S., Flores, E. and Herrero, A. (2014) ChIP analysis unravels an exceptionally wide distribution of DNA binding sites for the NtcA transcription factor in a heterocyst-forming cyanobacterium. BMC Genomics 15: 22.

Pollari, M., Ruotsalainen, V., Rantamaki, S., Tyystjarvi, E., and Tyystjarvi, T. (2009). Simultaneous inactivation of sigma factors $B$ and $D$ interferes with light acclimation of the cyanobacterium Synechocystis sp. strain PCC 6803. J Bacteriol 191: 39924001.

Puig, O., Caspary, F., Rigaut, G., Rutz, B., Bouveret, E., Bragado-Nilsson, E., Wilm, M., and Seraphin, B. (2001) The tandem affinity purification (TAP) method: a general procedure of protein complex purification. Methods 24: 218-229.

Price, G.D., Badger, M.R., Woodger, F.J., and Long, B.M. (2008). Advances in understanding the cyanobacterial $\mathrm{CO}_{2}$-concentrating-mechanism (CCM): functional components, $\mathrm{Ci}$ transporters, diversity, genetic regulation and prospects for engineering into plants. J Exp Bo. 59: 1441-1461.

Price, G.D. (2011) Inorganic carbon transporters of the cyanobacterial $\mathrm{CO}_{2}$ concentrating mechanism. Photosynth Res 109: 47-57. 
584 Ramasubramanian, T.S., Wei, T.-F. and Golden, J.W. (1994) Two Anabaena sp. strain PCC 7120 DNA-binding factors interact with vegetative cell- and heterocyst-specific genes. J Bacteriol 176: 1214-1223.

Rigaut, G., Shevchenko, A., Rutz, B., Wilm, M., Mann, M., and Seraphin, B. (1999) A generic protein purification method for protein complex characterization and proteome exploration. Na. Biotechnol 17: 1030-1032.

Rippka, R., Deruelles, J., Waterbury, J.B., Herdman, M., and Stanier, R.Y. (1979) Generic assignments, strain stories and properties of pure cultures of cyanobacteria. J Gen Microbiol 111: 1-61.

Schaefer, M.R., and Golden, S.S. (1989) Differential expression of members of a cyanobacterial psbA gene family in response to light. $J$ Bacteriol 171: 3973-3781.

Scheneider, K.L., Pollard, K.S., Baertsch, R., Pohl, A., and Lowe, T.M. (2006) The UCSC archaeal genome browser. Nucleic Ac Res 34: D407-D410.

Valladares, A., Rodríguez, V., Camargo, S., Martínez-Nöel, G.M., Herrero, A., and Luque, I. (2011) Specific role of the cyanobacterial PipX factor in the heterocysts of Anabaena sp. strain PCC 7120. J Bacteriol 193(5): 1172-1182.

Wang, H.L., Postier, B.L., and Burnap, R.L. (2004) Alterations in global patterns of gene expression in Synechocystis sp. PCC 6803 in response to inorganic carbon limitation and the inactivation of $n d h R$, a LysR family regulator. $J$ Biol Chem 279:

604

605

606 


\section{Figure legends:}

608 Fig. 1. Growth of the all3953 mutant. A, The growth rate constant $\left(\mu=\ln 2 / t_{\mathrm{d}}\right.$, where $t_{\mathrm{d}}$ is 609 the doubling time) was calculated from the increase of protein content determined in $6100.2 \mathrm{ml}$ samples of cultures. The table shows the mean and standard deviation from 3 611 independent cultures of each strain and condition. $\Delta$ all3953 is strain CSS74; CSS77 is 612 a control strain that carries the $\mathrm{Sm} / \mathrm{Sp}$-resistant determinant in a wild-type background.

613 B, Samples of cultures were photographed after 5 days of incubation under the 614 indicated conditions. HL, high light; LL, low light; HC, high carbon; LC, low carbon.

615

616 Fig. 2. Expression of $r b c L X S$ in the $\triangle$ all3953 mutant and complemented strain. 617 Northern analysis carried out with RNA from strains CSS77 (control) CSS74 ( $\triangle$ all3953) 618 and CSS74C (CSS74 complemented) was isolated from cells grown with HC (0) and 619 incubated for $1 \mathrm{~h}$ (1) with LC. The membranes were hybridized with an internal 620 fragment of the $r b c L$ gene (upper panels) and, as a loading and transfer control, of the $621 r n p B$ gene (lower panels). Arrowheads point to the main transcripts detected with the $622 r b c L$ gene probe (approximate sizes are indicated).

623

624 Fig. 3. Consensus All3953 binding sequence and $r b c L$ promoter. A, The primary 625 consensus motif based on 142 high confidence CSS57 ChIP-Seq peak sequences is 626 shown with indication of the probability of occurrence of each base along the 22-nt 627 sequence. $\mathrm{W}$ is $\mathrm{A}$ or $\mathrm{T} ; \mathrm{Y}$ is $\mathrm{C}$ or $\mathrm{T} ; \mathrm{B}$ is $\mathrm{C}, \mathrm{G}$ or $\mathrm{T}$. $\mathrm{B}$, Structure of the rbcLXS promoter 628 region. The transcription initiation point of the operon (+1) and the -10 and -35 boxes 629 (from Nierzwicki-Bauer et al., 1984) are indicated in red. The NtcA-binding site 630 (GTAN ${ }_{8}$ TAC) is indicated in green, and the three putative binding sites for All3953 (Box 631 I, Box II and Box III) are indicated in blue.

632 
633 Fig. 4. qRT-PCR analysis of the expression of selected photosynthesis and respiration-

634 related All3953 gene targets. Transcriptional response of the indicated genes to $C_{i}$ 635 limitation in the control (CSS77) and $\Delta$ all3953 mutant (CSS74) strains was 636 investigated. RNA was isolated from cells grown with $10 \mathrm{mM} \mathrm{NaHCO}{ }_{3}$-supplemented 637 medium bubbled with $1 \% \mathrm{CO}_{2}$ in air (0) incubated for $1 \mathrm{~h} \mathrm{(1)}$ or $3 \mathrm{~h} \mathrm{(3)}$ in $\mathrm{NaHCO}_{3}$-free 638 medium bubbled with air. Bars represent the mean transcript levels $( \pm$ standard 639 deviation) in three independent experiments.

640 
1 2

3

4

5

6

7

8

9

10

The LysR-type transcription factor PacR is a global regulator of photosynthetic carbon assimilation in Anabaena

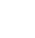

Silvia Picossi, Enrique Flores and Antonia Herrero*

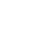

Instituto de Bioquímica Vegetal y Fotosíntesis, Consejo Superior de Investigaciones

Científicas and Universidad de Sevilla, Américo Vespucio 49, E-41092, Seville, Spain.

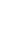

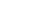

${ }^{*}$ Corresponding author. Tel.: +34 954489522. Fax: +34 954460165. E-mail address: herrero@ibvf.csic.es

Keywords: ChIP; Cyanobacteria; Oxygenic phototrophy; Photoprotection; RuBisCo

Running title: Photosynthetic carbon assimilation regulator

Accession link to data:

http://www.ncbi.nlm.nih.gov/geo/query/acc.cgi?token=afcxwkacxpydfax\&acc=GSE58861 
Cyanobacteria perform water-splitting photosynthesis and are important primary producers impacting the carbon and nitrogen cycles at global scale. They fix $\mathrm{CO}_{2}$ through ribulose bisphosphate carboxylase/oxygenase (RuBisCo) and have evolved a distinct $\mathrm{CO}_{2}$ concentrating mechanism (CCM) that builds high $\mathrm{CO}_{2}$ concentrations in the vicinity of RuBisCo favoring its carboxylase activity. Filamentous cyanobacteria such as Anabaena fix $\mathrm{CO}_{2}$ in photosynthetic vegetative cells, which donate photosynthate to heterocysts that rely on a heterotrophic metabolism to fix $\mathrm{N}_{2}$. CCM elements are induced in response to inorganic carbon limitation, a cue that exposes the photosynthetic apparatus to photodamage by over-reduction. An Anabaena mutant lacking the LysR-type transcription factor All3953 grows poorly and dies under high light. The rbcL operon encoding RuBisCo is induced upon carbon limitation in the wild type but not in the mutant. ChIP-Seq analysis was used to globally identify All3953 targets under carbon limitation. Targets include, besides $r b c L$, genes encoding CCM elements, photorespiratory pathway, photosystem- and electron transportrelated components, and factors, including flavodiiron proteins, with a demonstrated or putative function in photoprotection. QRT-PCR analysis of selected All3953 targets showed regulation in the wild type but not in the mutant. All3953 (PacR) is a global regulator of carbon assimilation in an oxygenic photoautotroph. 


\section{Introduction}

As the organisms that developed oxygenic photosynthesis, cyanobacteria have played a crucial role in Earth's history and the evolution of life in our planet. Indeed, the production of $\mathrm{O}_{2}$ as a result of cyanobacterial activity was responsible for the oxidation of the Earth's atmosphere about 2.5-2.3 billion years ago (Lyons et al., 2014). Furthermore, all the extant plastids of eukaryotic algae and plants are of cyanobacterial origin. Cyanobacteria were the first organisms to link the activity of the two types of photosystems (PSI and PSII), which allowed the generation of high electrochemical potential, and to combine them with a $\mathrm{H}_{2} \mathrm{O}$-splitting complex. Nowadays, most cyanobacteria are phototrophs relying on oxygenic photosynthesis to generate ATP and reducing equivalents for the fixation of $\mathrm{CO}_{2}$ and the assimilation of inorganic nitrogen. Indeed, they are responsible for an important fraction of the primary productivity in the Earth's oceans, where they are important $\mathrm{CO}_{2}$ and $\mathrm{N}_{2}$ fixers, thus impacting the $\mathrm{C}$ and $\mathrm{N}$ cycles at a global scale (Knoll 2008; Price et al., 2008).

The enzyme responsible for the bulk of $\mathrm{CO}_{2}$ fixation in the biosphere is ribulose1,5-bisphosphate carboxylase/oxygenase (RuBisCo), which has a relatively low affinity for $\mathrm{CO}_{2}$ and, moreover, it can also accept $\mathrm{O}_{2}$ as a substrate. Compensating for this relatively low performance, RuBisCo is considered the most abundant enzyme on Earth. As a carboxylase, RuBisCo catalyzes the first step of the Calvin-BensonBassham (CBB) cycle, i.e., the incorporation of atmospheric $\mathrm{CO}_{2}$ into ribulose-1,5bisphosphate to give two molecules of 3-phosphoglycerate. As an oxygenase, it catalyzes the incorporation of $\mathrm{O}_{2}$ into ribulose-bisphosphate, which produces 2phosphoglycolate that-can leads to photorespiration with a subsequent loss of fixed $\mathrm{C}$ and energy. To increase the efficiency of $\mathrm{CO}_{2}$ fixation, cyanobacteria have developed a distinct $\mathrm{CO}_{2}$ concentrating mechanism (CCM) constituted by inorganic carbon $\left(\mathrm{C}_{\mathrm{i}}\right)$ transporters that incorporate bicarbonate and $\mathrm{CO}_{2}$ into the cell, and a proteinaceous compartment, the carboxysome, where RuBisCo, together with carbonic anhydrase, is 
confined (Price et al., 2008; Cameron et al., 2014). Three high-affinitiy bicarbonate transporters (the ABC-type $\mathrm{Cmp}$, also called BCT1, and the $\mathrm{Na}^{+}$-dependent $\mathrm{BicA}$ and $\mathrm{SbtA}$ ), and two $\mathrm{CO}_{2}$ transporters (the high-affinity $\mathrm{NDH}-\mathrm{I}_{3}$ and the low-affinity $\mathrm{NDH}-\mathrm{I}_{4}$ ) have been identified in different cyanobacteria (see Price, 2011). Through CCM, Ci in the form of $\mathrm{CO}_{2}$ can concentrate in the vicinity of cyanobacterial RuBisCo, to allow high specific activity for production of 3-phosphoglycerate to levels much higher than in plants (Cameron et al., 2014). Indeed, components of cyanobacterial CCM have been transformed in tobacco, with the result of improved specific activity of $\mathrm{CO}_{2}$ fixation, which represents a step towards improved photosynthesis in plants (Lin et al., 2014).

In unicellular cyanobacteria, CCM elements are regulated by $C_{i}$ availability. Especially genes encoding $C_{i}$ transporters are induced, whereas the structural genes for carboxysome components and the rbcL/S genes encoding RuBisCo are only moderately responsive (see Price et al., 2008; Cameron et al., 2014). In chemotrophic bacteria the process of $\mathrm{CO}_{2}$ fixation and the response to $\mathrm{C}_{\mathrm{i}}$ limitation are usually controlled by LysR-type transcriptional regulators (LTTRs). The genes encoding the enzymes of the CBB cycle are usually found in clusters regulated by CbbR factors, which constitute a sub-family of LTTRs (Gibson and Tabita, 1996). In unicellular cyanobacteria, a number of $\mathrm{CbbR}$ homologs have been characterized. $\mathrm{CmpR}$ is an activator of the cmp genes (Nishimura et al., 2008), whereas CcmR (aka NdhR) acts as a transcriptional repressor of multiple genes encoding other $C_{i}$ transporters (e.g., Figge et al., 2001; Wang et al., 2004). A third type of CbbR-like protein, the activator of the RuBisCo genes, has not yet been identified in cyanobacteria.

The identification of a third type of CbbR-like protein, the activator of the RuBisCo genes, RbcR, has remained elusive in cyanobacteria.

Filamentous heterocyst-forming cyanobacteria, of which Anabaena sp. PCC 7120 (hereafter Anabaena) is a model organism, additionally have the capacity for cell differentiation to turn some $\mathrm{O}_{2}$-evolving photosynthetic cells of the filament into heterocysts, which are heterotrophic cells especialized in the fixation of atmospheric 
$N_{2}$. Thus, Anabaena is a truly pluricellular bacterium with different cell types specialized in different nutritional tasks that exchange nutrients and regulators and contribute to the performance of the filament as the organism unit (see Flores and Herrero, 2010). Nitrogen assimilation and heterocyst differentiation in Anabaena are regulated by the global transcription factor NtcA, which responds to the cellular C-to- $\mathrm{N}$ ratio, and the heterocyst-specific transcription factor HetR (see Herrero et al., 2013). The Anabaena genomic sequence includes three genes annotated as CbbR-like LTTRs (Kaneko et al., 2001). Of these, allo862 has been identified as $c m p R$, and its product activates the expression of the cmp operon (alr2877-alr2880) and the $c m p R$ gene itself in response to $C_{i}$ limitation (López-Igual et al., 2012). Notably, this regulation is effected in combination with $\mathrm{NtcA}$, thus revealing a mode of co-regulation by $\mathrm{C}$ and $\mathrm{N}$ availability (López-lgual et al., 2012). Furthermore, in Anabaena the rbcLXS operon encoding RuBisCo, which is moderately induced under $\mathrm{C}_{\mathrm{i}}$ limitation (López-Igual et al., 2012), is repressed in the heterocysts (Madan and Nierzwicki-Bauer, 1993), a regulation likely exerted by NtcA (Ramasubramanian et al., 1994; Picossi et al., 2014).

Here we have identified the CbbR-homolog All3953 as the activator of the RuBisCo-encoding operon in Anabaena. We have determined the All3953 regulon by ChIP-Seq, which has revealed that All3953 is a global regulator for $\mathrm{C}_{\mathrm{i}}$ assimilation genes and genes involved in protection of the photosynthetic apparatus against oxidative damage that are regulated by $\mathrm{Ci}$ availability.

\section{Results}

All3953, an RbcR-like factor in Anabaena sp. PCC 7120

To gain insight into the LTTR All3953 in Anabaena, the expression of the all3953 gene under different growth conditions was analyzed by northern blot. Three bands of hybridization corresponding to transcripts of ca. 1.9, 1.6 and $1.3 \mathrm{~kb}$, respectively, which appeared similarly represented before and after Ci limitation could be observed (Supp. 
Fig. 1A). On the other hand, all3953 expression did not significantly respond to $\mathrm{N}$ depletion (Supp. Fig. 1B). The latter result was consistent with previous global transcriptional studies (Ehira and Ohmori, 2006; Flaherthy et al., 2011) and with the lack of binding associated to all3953 of the $\mathrm{N}$-control transcriptional regulator NtcA upon combined nitrogen depletion (Picossi et al., 2014).

\section{Isolation and characterization of an all3953 mutant}

To study the role of All3953, a mutant strain bearing an inactivated version of all3953 was constructed (see Experimental procedures). In strain CSS74 most of the all3953 gene was deleted and the C.S3 gene cassette (encoding $\mathrm{Sm} / \mathrm{Sp}$ resistance) was introduced to facilitate segregation and maintenance of the mutation in Anabaena (Supp. Fig. 2A). As a control, strain CSS77 bearing the C.S3 gene cassette in the Anabaena plasmid alpha was also constructed. For cis complementation, a wild-type version of all3953 was transferred to strain CSS74 in an integrative plasmid, generating strain CSS74C (Supp. Fig. 2A).

Strain CSS74 exhibited poor growth under standard growth conditions with ammonium as a nitrogen source, and it formed short filaments in liquid medium, whereas strain CSS74C behaved similarly to CSS77 (not shown). To quantify the deleterious effect of the all3953 mutation, growth rates were calculated in liquid medium under different illumination and $\mathrm{C}_{i}$-supply conditions (Fig. 1). Growth rate of the control strain CSS77 was highest $\left(0.892\right.$ days $\left.^{-1}\right)$ under high light $(\mathrm{HL})$ and high carbon ( $\mathrm{HC}$ ), and was about $30 \%$ lower under the other tested conditions (Fig. 1A). In contrast, growth of strain CSS74 was severely affected under HL HC conditions (growth rate ca. $70 \%$ lower than that of the control) (Fig. 1A), under which it ended up dying after about 5 days (Fig. 1B). Under HL and low carbon (LC) or low light (LL) HC, the defect was close to $30 \%$ with regard to the control, although after prolonged incubation the mutant was more severely affected under HL LC. The defect was the 
smallest (ca. 15\%) under LL LC conditions (Fig. 1A,B). In solid mediumFinally, growth of strain CSS74 was similar, and similar to that of the control, in the presence of ammonium, nitrate or no combined nitrogen the effect of the $\mathrm{N}$ source on the growth of strain CSS74 was tested in solid medium-under LL LC and HL LC-conditions, whereasunder HL LC In LL LC growth of strain CSS74 was similar, and similar to that of the control, in the presence of ammonium, nitrate- or no combined nitrogen (Figure 1C). However, under HL LC a severe growth defect was observed with regard to the control with any of the tested nitrogen sources (not shownFig. 1C). It is worth noting that, because the CSS74 strain formed short filaments, colonies were observed at a lower chlorophyll concentration than in the control strain. In summary, the lack of All3953 had a deleterious effect on growth, especially under $\mathrm{HL}$ (and $\mathrm{HC}$ ) conditions.

To further characterize the growth defect of the all3953 mutant, the rate of oxygen evolution using $\mathrm{CO}_{2}$ as a final electron acceptor was measured under different illumination conditions in the CSS74 mutant in relation to the control strain CSS77. When exponentially-growing cells were incubated for $24 \mathrm{~h}$ under LL HC, the oxygen evolution rate was slightly lower in strain CSS74 in comparison to CSS77 (88 and $105 \mu \mathrm{mol} \mathrm{O} \mathrm{O}_{2} \cdot[\mathrm{mg} \mathrm{Chl}]^{-1} \cdot \mathrm{h}^{-1}$, respectively). Under $\mathrm{HL}$ the difference between the two strains was larger $\left(167\right.$, for CSS77, and 110 , for CSS74, $\left.\mu \mathrm{mol} \mathrm{O}_{2} \cdot[\mathrm{mg} \mathrm{Chl}]^{-1} \cdot \mathrm{h}^{-1}\right)$.

\section{Effect of all3953 mutation on rbcLXS expression}

To test the effect of the all3953 mutation on the expression of the rbcLXS operon, northern blot analysis was performed with RNA isolated from cells of the control and mutant strains grown with $\mathrm{HC}$ and transferred to LC conditions. After $1 \mathrm{~h}$ incubation with LC, a ca. 2-fold increase in the amount of the $r b c L X S$ transcripts could be observed in the control strain. No induction could be detected in the mutant (Fig. 2). In the complemented strain CSS74C the expression of $r b c L X S$ increased in LC similarly to the control (Fig. 2). These results indicated that the induction of the $r b c L X S$ operon 
upon $\mathrm{C}_{\mathrm{i}}$ deficiency was dependent on All3953 and that the defect in strain CSS74 was exclusively due to the lack of All3953.

\section{ChIP-Seq analysis of the All3953 targets}

To determine the DNA targets of All3953 at a genomic level, we used chromatin immunoprecipitation followed by high-throughput sequencing analysis. To this end, we constructed a strain (CSS57) expressing from the all3953 promoter a version of All3953 C-terminally fussed to TAP-tag (Rigaut et al., 1999), as well as a control strain (CSS68) expressing the TAP-tag alone under the control of the all3953 promoter (Supp. Fig. 2B, see Experimental procedures). Immunoprecipitation was carried out using cells of strains CSS57 and CSS68 grown with ammonium as the nitrogen source under $\mathrm{HC}$ conditions and incubated for $3 \mathrm{~h}$ with ammonium under LC conditions.

The analysis of the sequences resulted in a total of 142 All3953 binding regions, of which 127 were located in the chromosome, 10 in plasmid alpha, three in plasmid beta and two in plasmid gamma. Each binding region was ascribed to one or two genes according to the location (midpoint) of the region, and the relative location with respect to the assigned gene was also indicated (Table 1 and Supp. Table 1). A total of 175 genes were ascribed to the 142 binding regions. The binding regions were mostly located upstream of the ascribed genes (72\%), whereas $21 \%$ were intragenic and $7 \%$ were located downstream of genes. The results of the ChIP-Seq analysis are available at GEO accession number GSE5861 (http://www.ncbi.nlm.nih.gov/geo/query/acc.cgi?acc= GSE58861).

The 175 ascribed genes were classified according to their functional category (Table 2). Remarkably, there were 19 genes encoding proteins related to photosynthesis and respiration, and 21 genes encoding regulatory proteins, including All7179, a SigB homolog. The rest were mostly genes encoding hypothetical or unknown proteins $(42 \%)$, but also genes encoding proteins involved in translation, in 
biosynthesis of amino acids and cofactors, prosthetic groups and carriers, in transport, and in other cellular processes. Table 3 highlights All3953-binding regions related to photosynthesis and respiration among which, confirming our results of gene inactivation, the gene encoding the large subunit of the RuBisCo ( $r b c L$; binding region \#37) is included. The fact that a high number of genes involved in photosynthesis and C fixation, including $r b c L$, were identified as targets of RbcR suggests that this protein is a global transcription factor for photosynthetic $\mathrm{C}$ assimilation.

A CisFinder analysis of the primary consensus motif was carried out based on 142 high-confidence ChIP-Seq peak sequences (Fig. 3A). The consensus motif found has a dyad-symmetry architecture and matches the consensus of LysR-recognition binding sites (RBS) ( $\left.\mathrm{T}-\mathrm{N}_{11}-\mathrm{A}\right)$ (Maddocks and Oyston, 2008), as well as the consensus binding sites proposed for $\mathrm{CbbR}$ factors (TNA-N $\mathrm{N}_{7 / 8}-\mathrm{TNA}$ ). The primary motifs identified in the central $100 \mathrm{nt}$ of the binding regions are indicated in Supp. Table 1 (for some binding regions more than one motif have been identified).

To corroborate our ChIP-Seq analysis and to support the notion that All3953 is indeed a global regulator for $\mathrm{C}$ fixation genes, the expression levels of some of the photosynthesis- and $\mathrm{C}$-fixation-related target genes, its response to $\mathrm{C}_{\mathrm{i}}$ limitation and its dependence on All3953 was further analyzed by qRT-PCR (Fig. 4). Strains CSS77 and CSS74 were grown in ammonium and $\mathrm{HC}$ under standard light conditions (80 $\mu \mathrm{E} \cdot \mathrm{m}^{-2} \cdot \mathrm{s}^{-1}$ ) at $30^{\circ} \mathrm{C}$ up to the exponential phase. They were then transferred to medium with ammonium under LC conditions. As previously shown by northern analysis, transcription levels of the all3953 gene did not significantly change after $\mathrm{C}_{\mathrm{i}}$ deprivation in the control strain CSS77. As expected, all3953 transcript levels were not detectable in CSS74, corroborating that the all3953 mutation was segregated in this strain. The rbcL gene (alr1524) was 4.6-fold induced at $3 \mathrm{~h}$ after transfer to LC in strain CSS77, 
whereas no induction was observed in CSS74, thus corroborating the dependence on All3953. Interestingly, under $\mathrm{HC}$ the expression of $r b c L$ in the mutant was higher than in the control strain, suggesting that besides as an activator under LC, All3953 could be acting as a repressor of $r b c L$ under $\mathrm{HC}$ conditions.

ORF all4446 (flv4) was highly induced (about 100-fold), and its level was maximum $1 \mathrm{~h}$ after the shift to LC (Fig. 4). In the all3953 mutant, the basal transcription of all4446 in HC was about 8-fold lower than in the control strain, and it was only slightly induced (2-fold) upon the shift to LC. all3891 (flv1A) was induced about 6-fold 3 $\mathrm{h}$ after the shift to LC in the control strain, whereas only a 2 -fold induction was observed in the all3953 mutant. all1304 (bicarbonate transporter homolog) and alr4156 (NdhF homolog) were both highly induced (up to 30 - and 20-fold, respectively) upon transfer of strain CSS77 to LC. In contrast, no induction of alr4156 and only a small induction of all1304 took place in strain CSS74. Expression of alr4592 (psbAIII) increased about 5-fold upon $\mathrm{C}_{\mathrm{i}}$ deprivation in CSS77, but did not appreciably change in CSS74. The alr0223 (NdhA homolog) gene was about 2-fold induced under $\mathrm{C}_{\mathrm{i}}$ deprivation in CSS77 but not in CSS74. Finally, the expression of alr1004 (alanineglyoxylate aminotransferase) was repressed by 5 -fold under LC conditions in CSSL77 but not in CSS74. These results confirm that expression of the above studied genes is regulated, either positively or negatively, by All3953.

\section{Discussion}

We have identified the LTTR All3953 as the activator of the RuBisCo-encoding genes in the cyanobacterium Anabaena sp. PCC 7120 . All3953 appears to activate the rbcL operon under $C_{i}$ limitation and to repress it when $C_{i}$ is abundant. An LTTR factor regulating the expression of the rbcL operon has not, to our knowledge, been described in any cyanobacterium. The expression of all3953 does not respond to $C_{i}$ limitation (Supp. Fig. 1) and, indeed, no binding region of All3953 was found adscribed 
to all3953. Thus, the all3953 gene seems to belong to the non-autoregulated LTTRs. All3953 shares 28 and $26 \%$ identical residues with NdhR from Synechocystis sp. PCC 6803 and Synechococcus sp. PCC 7002 (CcmR), respectively.

By ChIP-Seq analysis of a strain bearing a TAP-tagged version of All3953, we have determined 142 All3953-bound regions at $3 \mathrm{~h}$ after transfer from high to low $\mathrm{C}_{\mathrm{i}}$ conditions, which have been assigned to 177 genes. Apart from genes encoding unknown or hypothetical proteins, the larger category is of genes encoding regulatory proteins, including the transcriptional regulators Alr0353 (a LTTR) and All4500 (CRPlike), the two-component response regulator All3348, the two-component sensor histidine-kinase All1145 and the group 2-sigma 70-type sigma factor All7179 (Supp. Table 1). Interestingly, when comparing to Synechocystis sigma factors, All7179 $\underline{(\mathrm{SigB} 4)}$ is more similar toa homolog of Synechocystis SigB, which, along with SigD has been shown to be important for PSII recovery in this unicellular cyanobacterium (Pollari et al., 2009). All3953 also binds upstream of genes patS and hetN, whose products regulate heterocyst differentiation (Supp. Table 1). The fact that All3953 binds to the promoter region of genes encoding other regulatory proteins suggests a wide role of this protein in the physiology of the organism.

In the promoter region of the $r b c L$ operon we have found three putative binding sites for All3953, Box I, Box II, and Box III (Fig. 3B) that resemble the consensus recognition sequence found by Cisfinder analysis (Fig. 3A). It is conceivable that, like in some other LTTRs these boxes combine repression and activation sites. In this regard, binding of All3953 to Box III, overlapping gene promoter elements, could be related to the repression of $r b c L$ observed under high $C_{i}$ (Fig. 4). On the other hand, as mentioned above, the $r b c L$ operon is repressed in heterocysts by the global transcriptional regulator NtcA, for which a binding site is found overlapping the operon TSP (Ramasubramanian et al., 1994; Picossi et al., 2014) (Figure 3B). It is conceivable that NtcA binding in these differentiated cells interfere with All3952-mediated activation. 

genes involved in other processes related to carbon assimilation, such as $C_{i}$ transport (all1304, encoding an homolog of the BicA bicarbonate transporter; alr4156 encoding a homolog of the NdhF3 subunit of the $\mathrm{NDH}_{-} 1_{3} \quad \mathrm{CO}_{2}$ uptake system; and alr0869 encoding a homolog of the NdhF4 subunit of the $\mathrm{NDH}-1_{4} \mathrm{CO}_{2}$ uptake system); components of the carboxysome shell (all0868, putative ccmK) and 2phosphoglycolate metabolism (alr1004 and alr2873, possibly related to photorespiration_[Eisenhut et al., 2008]). Notably, All3953 targets include also a number of genes encoding photosystem components, such as alr5154 ( $p s a A$, encoding the PSI core protein PsaA), alr3727 ( $p s b A l l$, encoding a component of form II of the PSIl core protein PsbA [D1]), alr4592 (psbAlll, encoding another component of form II of PsbA) and alr1216 (PSII 12 kD extrinsic protein PsbU), and genes related to PS activity. In the latter group are alr4149 (biliverdin reductase, putatively involved in phycobilisome -PSII antenna- synthesis), and genes that can participate in photosynthetic electron transfer, such as alr0223 and alr0348 ( $n d h A$ and $n d h D$, subunits of other putative NADH dehydrogenases), alr1576 (dehydrogenase subunit), all0737 (thioredoxin reductase), all1365 (CytM cytochrome), all4148 (ferredoxin I), all3891 and all4446 (flavodiiron proteins Flv1A and Flv4, respectively). (Besides in $\mathrm{CO}_{2}$ uptake, NdhF3 and NdhF4 can also participate in electron transfer.)

Reports on gene expression regulation by $\mathrm{C}_{\mathrm{i}}$ are scarce for Anabaena. However, in the unicellular cyanobacterium Synechocystis sp. PCC 6803 311 transcriptomic analysis has already shown down-regulation of some genes encoding 312 polypeptides of PSI and PSII complexes as well as of phycobilisome components, upon transfer to $\mathrm{C}_{\mathrm{i}}$ limitation conditions, likely as an adaptation to lower assimilatory 314 power demand, and up-regulation of some PSIl core polypeptides, interpreted as 315 adaptation to conditions of shortage of electron acceptors that could lead to 316 photodamage and increased turnover of PS core components (Wang et al., 2004). Our 317 analysis extends the array of photosynthetic genes responding to $\mathrm{C}_{\mathrm{i}}$ limitation, 
remarkably to include the core PSI reaction center $p s a A$ gene. Moreover, except for alr1004 that responds negatively, all the Anabaena photosynthetic genes mentioned above increase expression upon the shift to $C_{i}$ limitation.

Noteworthy, for the majority of photosynthetic gene targets of All3953 in Anabaena, a function in protection against reactive oxygen species, which can be generated by $\mathrm{C}_{\mathrm{i}}$ limitation or exposure to $\mathrm{HL}$, has either been described or could be predicted. Thus, the $p s b A l l$ and $p s b A I I I$ genes are induced under $\mathrm{HL}$ in the unicellular Synechococcus sp. PCC 7942, and cells cultured under HL showed more form II, and less form I (encoded by psbAl), of D1 compared to cells under LL (Schaefer and Golden, 1989). Regarding flavodiiron proteins, genes, flv1A, flv3A, and specially flv2 and flv4 of Anabaena have been shown up-regulated in vegetative cells in low $\mathrm{Ci}$, and $f / v 1 A$ and flv3A also in high light, whereas $f / v 1 B$ and $f / v 3 B$ are expressed exclusively in heterocysts (Ermakova et al., 2013). Whereas Flv1A and Flv3A appear involved in photoreduction of oxygen to water by removing excess electrons from PSI through NAD(P)H dehydrogenases, Flv2 and Flv4 could have a role in photoprotection of PSII under low Ci (Ermakova et al., 2013). Regarding photorespiration, it has also been considered to have a role in removal of excess $\mathrm{O}_{2}$ (Eisenhut et al., 2008). To the best of our knowledge, the regulator responsible for the response to $C_{i}$ availability of any photosynthetic gene has not been identified in cyanobacteria (oxygenic phototrophs). Our ChIP-Seq and expression analysis indicate that All3953 is a regulator of photosynthetic genes in Anabaena.

The growth rate of Anabaena is highest under $\mathrm{HL} \mathrm{HC}$ conditions (Fig. 1), implying that this cyanobacterium has mechanisms to get profit of $\mathrm{HC}$ while counteracting HL stress. The all3953 mutant strain CSS74 exhibited a growth defect in all the conditions tested, but especially under $\mathrm{HL}$, where it ends-up dying (Fig. 1). This shares the idea that in Anabaena All3953 is required to cope with HL stress. The effect of the lack of All3953 seems more detrimental in relation to impaired photoprotection than to impaired $C_{i}$ scavenging (preference of the mutant for LL LC over HL HC 
conditions). Indeed, even in LL, the mutant seems to perform slightly better with LC than with HC (Fig. 1). Although LC could suppose a limitation of electron acceptors, an increased rate of photorespiration under LC together with the fact that some of the All3953 targets that could cope with excess oxygen are residually induced upon the transfer from HC to LC in the CSS74 mutant (Fig. 4) could contribute to the preference of this strain for LC over $\mathrm{HC}$, especially under $\mathrm{HL}$.

Our results show that in Anabaena the responses to $\mathrm{C}_{\mathrm{i}}$ availability include regulation of genes encoding elements of CCM and RuBisCo, but also of photosynthetic genes to adjust generation of assimilatory power while preserving the photosynthetic apparatus from oxidative damage, which is specially relevant in oxygenic phototrophs. Because All3953 is a transcriptional regulator globally coordinating these responses, we have named it PacR (Photosynthetic assimilation of carbon Regulator).

\section{Experimental procedures}

Strains

Anabaena sp. strain PCC 7120 was grown photoautrophically at $30^{\circ} \mathrm{C}$ with illumination $\left(80 \mu \mathrm{E} \cdot \mathrm{m}^{-2} \cdot \mathrm{s}^{-1}\right)$ in liquid BG110 medium (Rippka et al., 1979) supplemented with $3 \mathrm{mM}$ $\mathrm{NH}_{4} \mathrm{Cl}, 6 \mathrm{mM}$ TES buffer and $10 \mathrm{mM} \mathrm{NaHCO}_{3}$ and bubbled with a mixture of $\mathrm{CO}_{2}$ and air $(1 \% \mathrm{v} / \mathrm{v})(\mathrm{HC})$. Other conditions used were no $\mathrm{NaHCO}_{3}$ supplement and bubbling with air (LC); $12 \mu \mathrm{E} \cdot \mathrm{m}^{-2} \cdot \mathrm{s}^{-1}(\mathrm{LL}) ; 175 \mu \mathrm{E} \cdot \mathrm{m}^{-2} \cdot \mathrm{s}^{-1}(\mathrm{HL})$. For growth on plates illumination was $9 \mu \mathrm{E} \cdot \mathrm{m}^{-2} \cdot \mathrm{s}^{-1}(\mathrm{LL})$ or $34 \mu \mathrm{E} \cdot \mathrm{m}^{-2} \cdot \mathrm{s}^{-1}(\mathrm{HL})$. For the mutants generated in this work, antibiotics were used at the following concentrations: Sm, $2 \mu \mathrm{g} \mathrm{ml}^{-1}$; Sp, $2 \mu \mathrm{g} \mathrm{ml}^{-1}$; and $\mathrm{Nm}, 25 \mu \mathrm{g} \mathrm{ml}^{-1}$ for bubbled cultures; and Sm, $5 \mu \mathrm{g} \mathrm{ml}^{-1}$; Sp, $5 \mu \mathrm{g} \mathrm{ml}^{-1}$; and $\mathrm{Nm}$, $40 \mu \mathrm{g} \mathrm{ml}^{-1}$ for cultures in solid medium.

\section{Strain construction}


To construct a mutant of the all3953 gene, the $5^{\prime}$ and $3^{\prime}$ end of the gene, along with the flanking regions, were PCR amplified using chromosomal DNA of PCC 7120 as the template and primers all3953-14 (Bglll) and all3953-15 (Sall), and primers all3953-16 (Sall) and all3953-17 (Pstl), respectively (all primers are specified in Supp. Table 2). The PCR products were digested with Sall and ligated. The resulting mixture was used as a template for overlapping PCR with primers all3953-14 and all3953-17. The new PCR product was digested with Bglll and Pstl and ligated to the Bglll-Pstl-digested pRL271 (Black et al., 1993), obtaining plasmid pCSS161. Plasmid pCSS161 was digested with Spel and the 2-kb Sm ${ }^{r} \mathrm{Sp}^{r}$ gene cassette C.S3, excised with Xbal from pCSE120 [S.K3/L.HEH2 (BamHI)/C.S3 (BamHI); nomenclature as in (Elhai and Wolk, 1988)], was inserted obtaining plasmid pCSS162. Plasmid pCSS162 was transferred to strain PCC 7120 by conjugation (Elhai et al., 1997). Exconjugants resistant to Sm and $\mathrm{Sp}$, which had the $\Delta$ all3953::C.S3 construct integrated by double recombination were selected, obtaining strain CSS74. The segregation of the mutation was tested by PCR (Supp. Fig. 2) with primers all3953-14, all3953-15, all3953-17 and all3953-20.

To construct a control strain expressing $\mathrm{Sm}^{r}$ and $\mathrm{Sp}^{r}$ plasmid pCSS163, a derivative of plasmid pCSEL24 (Olmedo-Verd et al., 2006) containing the C.S3 gene cassette, was transferred to Anabaena by conjugation. Exconjugants that had the pCSS163 integrated in the alpha plasmid of Anabaena were selected, obtaining the strain CSS77 (Supp. Fig. 2).

To complement the all3953 mutation of strain CSS74, a DNA fragment encompassing the whole all3953 gene and sequences upstream from it was amplified by PCR using the primer pair all3953-24/all3953-25, both including EcoRI sites, and strain PCC 7120 DNA as the template. This fragment was cloned in the EcoRI site of the mobilizable $\mathrm{Nm}^{r}$ encoding vector pRL424 (Elhai and Wolk, 1988) producing plasmid pCSS164, which was transferred to strain CSS74 by conjugation followed by selection for $\mathrm{Nm}^{\mathrm{r}}$. The genomic structure of the exconjugants in the all3953 region (Supp. Fig. 2) was corroborated by PCR. 

upstream region) was PCR-amplified with primers all3953-11 and all3953-12 and DNA of PCC 7120 as the template. The TAP-tag was PCR-amplified with primers TAPtag-1 and TAPtag-2 using DNA of plasmid pBS1479 as the template (Puig et al., 2001). The two PCR products were digested with Sall and ligated, after which the ligation product was used as the template for an overlapping PCR using primers all3953-11 and TAPtag-2. The PCR product was digested with Pstl and ligated to the mobilizable vector pCSV3 (Valladares et al., 2011) digested with Pstl, rendering plasmid pCSS107.

To construct a control strain with the TAP-tag under the control of the all3953 promoter, a 0.4-kb region upstream of all3953 was PCR-amplified using primers all3953-11 and all3953-18 and DNA of pCSS107 as the template. The PCR product was digested with Sall and ligated to the PCR-amplified TAP-tag digested with Sall, after which the ligation product was used as the template for an overlapping PCR using primers all3953-11 and TAPtag-2. The PCR product was digested with Pstl and ligated to Pstl-digested pCSV3 to give plasmid pCSS157. Plasmids pCSS107 and pCSS157 were transferred by conjugation to strain PCC 7120 and single Sm $\mathrm{Sp}^{r}$ recombinants were selected, obtaining strain CSS57 and CSS68, respectively. Western blots using Peroxidase-Anti-Peroxidase Soluble Complex (PAP, Sigma-Aldrich) were performed to ensure that the two strains expressed the TAP-tag (Supp. Fig. 2B).

\section{Chromatin immunoprecipitation}

Cells of strains CSS57 growing exponentially $\left(3-5 \mu \mathrm{g} \mathrm{Chl} \cdot \mathrm{ml}^{-1}\right)$ in the light (80 $\left.\mu \mathrm{E} \cdot \mathrm{m}^{-2} \cdot \mathrm{s}^{-1}\right)$ in medium supplemented with $2 \mu \mathrm{g} \cdot \mathrm{ml}^{-1} \mathrm{Sm}$ and $\mathrm{Sp}$, in $\mathrm{HC}$ conditions were incubated with LC for $3 \mathrm{~h}$. Formaldehyde was then added to the cultures to a final concentration of $1 \%$, and the cultures were incubated for $15 \mathrm{~min}$. Glycine was added at $125 \mathrm{mM}$ final concentration and the incubation was continued for $5 \mathrm{~min}$ to stop the fixing reaction. The cells were then filtered, washed with cold TBS $(20 \mathrm{mM}$ Tris- $\mathrm{HCl}, \mathrm{pH}$ 
frozen in liquid nitrogen and stored at $-20^{\circ} \mathrm{C}$ until used. Pellets corresponding to about $25 \mathrm{ml}$ of culture were resuspended in $500 \mu \mathrm{l}$ of lysis buffer $(50 \mathrm{mM}$ HEPES-KOH, pH 7.5, $140 \mathrm{mM} \mathrm{NaCl}, 1 \mathrm{mM}$ EDTA, $1 \%$ Triton X-100, $0.1 \%$ sodium deoxycholate, supplemented with Mini EDTA-free protease inhibitor cocktail [Roche]) and, after addition of $150 \mu \mathrm{l}$ of glass beads (acid-washed, 425-600 $\mu \mathrm{m}$ [Sigma]), the cells were broken in a multivortexer at $2,000 \mathrm{rpm}$ for $1 \mathrm{~h}$ at $4^{\circ} \mathrm{C}$. The cell lysates were collected by centrifugation and the extracts were subjected to sonication to shear the DNA to about 300-bp fragments (60 cycles of $10 \mathrm{~s}, 20 \mathrm{~s}$ ice, $15 \%$ amplitude, in a Branson Digital Sonifier). After centrifugation to eliminate cell debris, the whole-cell extracts were stored at $-20^{\circ} \mathrm{C}$ or immediately used for immunoprecipitation.

Immunoprecipitation of DNA was carried out as described (Picossi et al., 2014), with some modifications. Whole-cell extracts were prepared at $4 \mathrm{mg} \cdot \mathrm{ml}^{-1}$ of total protein with lysis buffer (in $500 \mu$ l total volume). A $50-\mu l$ sample was taken as the input sample, and the extracts were incubated with $15 \mu \mathrm{l}$ lgG-conjugated Dynabeads (about $6 \mu \mathrm{g}$ IgG) at $4^{\circ} \mathrm{C}$ with rotation for $12-14 \mathrm{~h}$. The washes of the Dynabeads, as well as the elution of the immunoprecipitated material, the crosslinking reversion and the isolation of the DNA were performed as in (Picossi et al., 2014).

\section{Massive sequencing of the immunoprecipitated DNA}

Input and ChIP DNA samples were sent for sequencing to the Functional Genomics Core Facility of the Institute for Research in Biomedicine, Barcelona (Spain). Next generation sequencing was carried out using Illumina's sequencing technology. ChIP DNA Sample Prep Kit (Illumina) was used for library preparation. Libraries were loaded at $8 \mathrm{pM}$ concentration into the flow cell using the Cluster Station running recipe V7 with the Single-Read Cluster Generation Kit v4 (all Illumina). The flow cell was loaded into the Genome Analyzer II and samples were sequenced for 120 nucleotides from a single end using the Sequencing Kit v5 and recipe v8 (all Illumina). Manufacturer's 
recommendations were strictly followed. Illumina sequencing data were pre-processed with the standard Illumina pipeline version 1.5 and sequences were aligned to the PCC 7120 genome (http://genome.microbedb.jp/cyanobase/Anabaena) with the Bowtie software 0.12 .5 (Langmead et al., 2009). The analysis of the results were carried out using the Triform algorithm (Kornacker et al., 2012) as in (Picossi et al., 2014). The sequences in the ChIP samples of strain CSS68 (TAP control) were used as the background of the sequences found for strain CSS57 (All3953-TAP), and thus to determine the specific binding regions of All3953-TAP in the genome of Anabaena. The binding regions were visualized and analyzed using the UCSC Microbial Genome Browser (Scheneider et al., 2006). They were ascribed to one or two genes, in case it was not possible to ascribe them to only one, and classified as upstream of the gene, if the midpoint of the binding region was located upstream of the start of the gene, internal, if the midpoint of the binding region was inside the gene, or downstream, if the midpoint of the binding region was located downstream of the end of the gene to which it had been ascribed. 
473 Isolation of total RNA from Anabaena was done as described previously (Mohamed

474

475 and Jansson, 1989). Northern analysis was performed as described previously (LópezIgual et al., 2012).

For qRT-PCR, $750 \mathrm{ng}$ of DNA-free RNA samples were used for all the PCR primer pairs. For the RT reaction, the Quantitech Reverse transcription kit (Qiagen), with the Random Hexamer Primer mix (100 ng per sample) (Bioline) was used. The cDNA produced was diluted 7.5 times to use $2 \mu$ of cDNA per PCR reaction. PCR was done using the Quantimix Easy SYG Kit (Biotools) (SYBR green I) in a iCycler iQ MultiColor Real Time PCR Detection System (Bio-Rad). The abundance of a transcript in the RNA sample was calculated as: abundance $=2^{\wedge}[\mathrm{Ct}($ sample $)-\mathrm{Ct}($ control)], where the RNA sample of the control strain CSS77 in $\mathrm{HC}$ condition (0) was used as the control.

\section{Oxygen evolution}

2-ml samples of exponentially grown cultures in HC LL or HC HL conditions were used to measure $\mathrm{O}_{2}$ evolution with an $\mathrm{O}_{2}$ electrode calibrated with culture medium and $\mathrm{Na}_{2} \mathrm{~S}_{2} \mathrm{O}_{4}$ as the reducing agent. $\mathrm{O}_{2}$ production was measured in the light (400 $\left.\mu \mathrm{E} \cdot \mathrm{m}^{-2} \cdot \mathrm{s}^{-1}\right)$ after a seven-minute incubation in the dark.

\section{Acknowledgments}

This work was supported by grants BFU2010-17980 and BFU2013-44686-P from the Spanish government, co-financed by FEDER. The authors are grateful to K. Kornacker for carrying out the Triform and CisFinder analyses, and to $\mathrm{H}$. Auer and I. Pons, from the Functional Genomics Core Facility of the IRB, Barcelona (Spain); to F. MonjeCasas and Yagut Allahverdiyeva-Rinne for critical reading of the manuscript and to $\mathrm{M}$. J. Huertas and A. Torrado for help with $\mathrm{O}_{2}$ production measurements.

\section{REFERENCES}


Black, T.A., Cai, Y., and Wolk C.P. (1993) Spatial expression and autoregulation of hetR, a gene involved in the control of heterocyst development in Anabaena. Mol Microbiol 9: 77-84.

Cameron, C.J., Sutter, M., and Kerfeld, C.A. (2014) The carboxysome: Function, structure and cellular dynamics. The Cell Biology of Cyanobacteria, eds. Flores E, Herrero A (Caister Academic Press, Norfolk), pp. 171-188.

Ehira, S., and Ohmori, M, (2006) NrrA, a nitrogen-responsive response regulator facilitates heterocyst development in the cyanobacterium Anabaena sp. strain PCC 7120. Mol Microbiol 59: 1692-1703.

Elhai., J., Vepritskiy, A., Muro-Pastor, A.M., Flores, E, and Wolk, C.P. (1997) Reduction of conjugal transfer efficiency by three restriction activities of Anabaena sp. strain PCC 7120. J Bacteriol 179: 1998-2005.

Eisenhut, M., Ruth, W., Haimovich, M., Bauwe, H., Kaplan, A., and Hagemann, M. (2008) The photorespiratory glycolate metabolism is essential for cyanobacteria and might have been conveyed endosymbiotically to plants. Proc Natl Acad Sci USA 105: 17199-17204.

Elhai, J., and Wolk, C.P. (1988) A versatile class of positive-selection vectors based on the nonviability of palindrome-containing plasmids that allows cloning into long polylinkers. Gene 68: 119-138.

Ermakova, M., Battchikova, N., Allahverdiyeva, Y., and Aro, E.M. (2013) Novel heterocyst-specific flavodiiron proteins in Anabaena sp. PCC 7120. FEBS Lett 587: 82-7.

Figge, R.M., Cassier-Chauvat, C., Chauvat, F., and Cerff, R. (2001) Characterization and analysis of an $\mathrm{NAD}(\mathrm{P}) \mathrm{H}$ dehydrogenase transcriptional regulator critical for the survival of cyanobacteria facing inorganic carbon starvation and osmotic stress. $\mathrm{Mol}$ Microbiol 39: 455-68.

Flaherty, B.L., Van Nieuwerburgh, F., Head, S.R., and Golden, J.W. (2011) Directional RNA deep sequencing sheds new light on the transcriptional response of Anabaena sp. strain PCC 7120 to combined-nitrogen deprivation. BMC Genomics 12: 332.

Flores, E., and Herrero, A. (2010) Compartmentalized function through cell differentiation in filamentous cyanobacteria. Nat Rev Microbiol 8: 39-50.

Gibson, J.L., and Tabita, F.R. (1996) The molecular regulation of the pentose phosphate pathway in proteobacteria and cyanobacteria. Arch Microbiol 166: 141150.

Herrero, A., Picossi, S., and Flores, E. (2013) Gene Expression during heterocyst differentiation. Adv Bot Res 65: 281-329.

Kaneko, T., Nakamura, Y., Wolk, C.P., Kuritz, T., Sasamoto, S., and Watanabe, A. (2001) Complete genomic sequence of the filamentous nitrogen-fixing cyanobacterium Anabaena sp. strain PCC 7120. DNA Res 8: 205-213.

Knoll, A.H. (2008) Cyanobacteria and Earth history. The Cyanobacteria: Molecular Biology, Genomics and Evolution, eds. Herrero A, Flores E (Caister Academic Press, Norfolk), pp. 1-19.

Kornacker, K., Rye, M.B., Handstad, T., and Drablos, F. (2012) The Triform algorithm: improved sensitivity and specificity in ChIP-Seq peak finding. BMC Bioinformatics 13: 176.

Langmead, B., Trapnell, C., Pop, M., and Salzberg, S.L. (2009) Ultrafast and memoryefficient alignment of short DNA sequences to the human genome. Genome Biol 10: R25.

Lin, M.T., Occhialini, A., Andralojc, P.J., Parry, M.A.J., and Hanson, M.R. (2014) A faster Rubisco with potential to increase photosynthesis in crops. Nature 513: 547550.

López-Igual, R., Picossi, S., López-Garrido, J., Flores, E., and Herrero, A. (2012) N and $\mathrm{C}$ control of $\mathrm{ABC}$-type bicarbonate transporter $\mathrm{Cmp}$ and its LysR-type 
transcriptional regulator $\mathrm{CmpR}$ in a heterocyst-forming cyanobacterium, Anabaena sp. Environ Microbiol 14: 1035-1048.

Lyons, T.W., Reinhard, C.T., and Planavsky, N.J. (2014) The rise of oxygen in Earth's early ocean and atmosphere. Nature 506: 307-315.

Madan, A.P., and Nierzwicki-Bauer, S.A. (1993) In situ detection of transcripts for ribulose-1,5-bisphosphate carboxylase in cyanobacterial heterocysts. J Bacteriol 175: 7301-7306.

Maddocks, S.E., and Oyston, P.C. (2008) Structure and function of the LysR-type transcriptional regulator (LTTR) family proteins. Microbiology 154: 3609-3623.

Mohamed, A., and Jansson, C. (1989) Influence of light on accumulation of photosynthesis-specific transcripts in the cyanobacterium Synechocystis 6803. Plant Mol Biol 13: 693-700.

Nierzwicki-Bauer, S.A., Curtis, S.E., and Haselkorn, R. (1984) Cotranscription of genes encoding the small and large subunits of ribulose-1,5-bisphosphate carboxylase in the cyanobacterium Anabaena 7120. Proc Natl Acad Sci USA 81: 5961-5965.

Nishimura, T., Takahashi, Y., Yamaguchi, O., Suzuki, H., Maeda, S., and Omata, T. (2008) Mechanism of low $\mathrm{CO}_{2}$-induced activation of the $\mathrm{cmp}$ bicarbonate transporter operon by a LysR family protein in the cyanobacterium Synechococcus elongatus strain PCC 7942. Mol Microbiol 68: 98-109.

Olmedo-Verd, E., Muro-Pastor, A.M., Flores, E., and Herrero, A. (2006) Localized induction of the ntcA regulatory gene in developing heterocysts of Anabaena sp. strain PCC 7120. J Bacteriol 188: 6694-6649.

Picossi, S., Flores, E. and Herrero, A. (2014) ChIP analysis unravels an exceptionally wide distribution of DNA binding sites for the NtcA transcription factor in a heterocyst-forming cyanobacterium. BMC Genomics 15: 22.

Pollari, M., Ruotsalainen, V., Rantamaki, S., Tyystjarvi, E., and Tyystjarvi, T. (2009). Simultaneous inactivation of sigma factors $B$ and D interferes with light acclimation of the cyanobacterium Synechocystis sp. strain PCC 6803. J Bacteriol 191: 39924001.

Puig, O., Caspary, F., Rigaut, G., Rutz, B., Bouveret, E., Bragado-Nilsson, E., Wilm, M., and Seraphin, B. (2001) The tandem affinity purification (TAP) method: a general procedure of protein complex purification. Methods 24: 218-229.

Price, G.D., Badger, M.R., Woodger, F.J., and Long, B.M. (2008). Advances in understanding the cyanobacterial $\mathrm{CO}_{2}$-concentrating-mechanism (CCM): functional components, $\mathrm{Ci}$ transporters, diversity, genetic regulation and prospects for engineering into plants. J Exp Bo. 59: 1441-1461.

Price, G.D. (2011) Inorganic carbon transporters of the cyanobacterial $\mathrm{CO}_{2}$ concentrating mechanism. Photosynth Res 109: 47-57.

Ramasubramanian, T.S., Wei, T.-F. and Golden, J.W. (1994) Two Anabaena sp. strain PCC 7120 DNA-binding factors interact with vegetative cell- and heterocyst-specific genes. J Bacteriol 176: 1214-1223.

Rigaut, G., Shevchenko, A., Rutz, B., Wilm, M., Mann, M., and Seraphin, B. (1999) A generic protein purification method for protein complex characterization and proteome exploration. Na. Biotechnol 17: 1030-1032.

Rippka, R., Deruelles, J., Waterbury, J.B., Herdman, M., and Stanier, R.Y. (1979) Generic assignments, strain stories and properties of pure cultures of cyanobacteria. J Gen Microbiol 111: 1-61.

Schaefer, M.R., and Golden, S.S. (1989) Differential expression of members of a cyanobacterial $p s b A$ gene family in response to light. J Bacteriol 171: 3973-3781.

Scheneider, K.L., Pollard, K.S., Baertsch, R., Pohl, A., and Lowe, T.M. (2006) The UCSC archaeal genome browser. Nucleic Ac Res 34: D407-D410.

Valladares, A., Rodríguez, V., Camargo, S., Martínez-Nöel, G.M., Herrero, A., and Luque, I. (2011) Specific role of the cyanobacterial PipX factor in the heterocysts of Anabaena sp. strain PCC 7120. J Bacteriol 193(5): 1172-1182. 


\section{Page 45 of 54}

608 Wang, H.L., Postier, B.L., and Burnap, R.L. (2004) Alterations in global patterns of 609

610

611

612

613

614 gene expression in Synechocystis sp. PCC 6803 in response to inorganic carbon limitation and the inactivation of $n d h R$, a LysR family regulator. $J$ Biol Chem 279: 5739-5751. 
615 Figure legends:

616 Fig. 1. Growth of the all3953 mutant. A, The growth rate constant $\left(\mu=\ln 2 / t_{\mathrm{d}}\right.$, where $t_{\mathrm{d}}$ is 617 the doubling time) was calculated from the increase of protein content determined in $6180.2 \mathrm{ml}$ samples of cultures. The table shows the mean and standard deviation from 3 619 independent cultures of each strain and condition. $\Delta a / l 3953$ is strain CSS74; CSS77 is 620 a control strain that carries the Sm/Sp-resistant determinant in a wild-type background.

621 B, Samples of cultures were photographed after 5 days of incubation under the

indicated conditions. $G$, Growth in solid medium (no $\mathrm{NaHCO}_{3}$ ) with $3 \mathrm{mM} \mathrm{NH}_{4} \mathrm{Cl}(\mathrm{A})$, $17.6 \mathrm{mM} \mathrm{NaNO}_{3}(\mathrm{~N})$, or no combined nitrogen (-N). 5- $\mu$ l drops, containing 50, 5, 0.5 or 0.05 ng Chl, were spotted, incubated for 14 days and photographed. HL, high light; LL, low light; HC, high carbon; LC, low carbon.

Fig. 2. Expression of $r b c L X S$ in the $\triangle$ all3953 mutant and complemented strain. Northern analysis carried out with RNA from strains CSS77 (control) CSS74 (4all3953) and CSS74C (CSS74 complemented) was isolated from cells grown with HC (0) and incubated for $1 \mathrm{~h}$ (1) with LC. The membranes were hybridized with an internal fragment of the $r b c L$ gene (upper panels) and, as a loading and transfer control, of the rnpB gene (lower panels). Arrowheads point to the main transcripts detected with the rbcL gene probe (approximate sizes are indicated).

Fig. 3. Consensus All3953 binding sequence and rbcL promoter. A, The primary consensus motif based on 142 high confidence CSS57 ChIP-Seq peak sequences is shown with indication of the probability of occurrence of each base along the 22-nt sequence. $\mathrm{W}$ is $\mathrm{A}$ or $\mathrm{T} ; \mathrm{Y}$ is $\mathrm{C}$ or $\mathrm{T} ; \mathrm{B}$ is $\mathrm{C}, \mathrm{G}$ or $\mathrm{T} . \mathrm{B}$, Structure of the rbcLXS promoter region. The transcription initiation point of the operon (+1) and the -10 and -35 boxes 


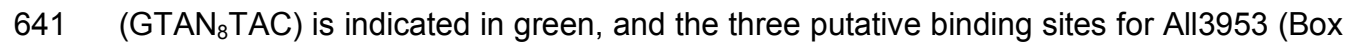

642 I, Box II and Box III) are indicated in blue.

643

644 Fig. 4. qRT-PCR analysis of the expression of selected photosynthesis and respiration645 related All3953 gene targets. Transcriptional response of the indicated genes to $C_{i}$ 646 limitation in the control (CSS77) and $\Delta$ all3953 mutant (CSS74) strains was 647 investigated. RNA was isolated from cells grown with $10 \mathrm{mM} \mathrm{NaHCO}$-supplemented 648 medium bubbled with $1 \% \mathrm{CO}_{2}$ in air (0) incubated for $1 \mathrm{~h}(1)$ or $3 \mathrm{~h} \mathrm{(3)}$ in $\mathrm{NaHCO}_{3}$-free 649 medium bubbled with air. Bars represent the mean transcript levels ( \pm standard 650 deviation) in three independent experiments.

651 
Table 1. Results of the ChIP-Seq analysis of All3953 binding to DNA at $3 \mathrm{~h}$ after $\mathrm{C}_{\mathrm{i}}$ limitation

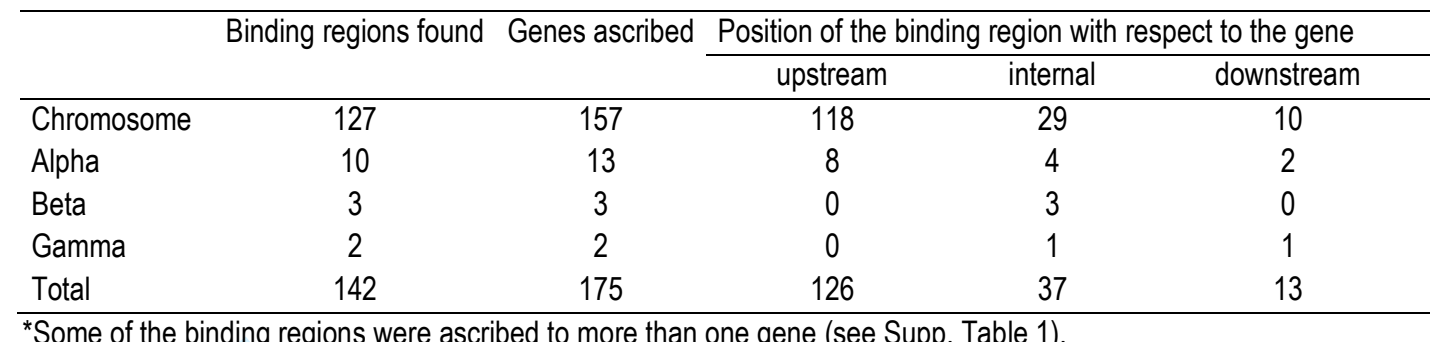

${ }^{*}$ Some of the binding regions were ascribed to more than one gene (see Supp. Table 1). 
Table 2. Functional categories of the genes ascribed to the All3953 binding regions.

\begin{tabular}{lc}
\hline Functional category & Number \\
\hline Amino acid biosynthesis & 5 \\
Biosynthesis of cofactors, prosthetic groups, and carriers & 4 \\
Cell envelope & 2 \\
Cellular processes & 5 \\
Central intermediary metabolism & 3 \\
DNA replication, recombination and repair & 3 \\
Energy metabolism & 4 \\
Other categories & 19 \\
Photosynthesis and respiration & 19 \\
Purines, pyrimidines, nucleosides and nucleotides & 2 \\
Regulatory proteins & 21 \\
Translation & 9 \\
Transport and binding proteins & 9 \\
Unknown and hypothetical proteins & 4
\end{tabular}


Table 3. All3953-binding regions assigned to photosynthesis and respiration-related genes.

\begin{tabular}{|c|c|c|c|c|c|c|c|c|}
\hline BR & NLQ & $\mathrm{LOC}$ & GENE & POSITION & FUNCTION & ST & START & SEQ \\
\hline 7 & 172,84 & 239694 & alr0223* & upstream & NADH dehydrogenase subunit $1 ; \mathrm{NdhA}$ & + & 239712 & AGGTATTAGTTTAACTAATGTT \\
\hline 12 & 38,58 & 398948 & alr0348 & upstream close & NADH dehydrogenase subunit 4; NdhD & + & 398912 & AACAATTCCTTAATATAATGTA \\
\hline 19 & 62,81 & 859596 & all0737 & upstream & thioredoxin reductase & - & 859596 & ATTCATAAAAGCGTTTTATATC \\
\hline \multirow[t]{2}{*}{25} & 238,45 & 997693 & all0868 & upstream & $\mathrm{CO}_{2} \mathrm{C}$ & + & 997698 & ATGTATAAGTTTTATTAATATG \\
\hline & & & alr0869 & upstream & NADH dehydrogenase subunit 5 & & & \\
\hline 27 & 66,90 & 1175262 & alr1004* & upstream & alanine--glyoxylate aminotransferase & + & 1175259 & GTATATAGGCGATCATTATGGC \\
\hline 31 & 36,15 & 1433154 & alr1216 & upstream & photosystem II 12 kD extrinsic protein PsbU & + & 1433147 & AAATATTGTGAGCATTAATAAG \\
\hline 34 & 385,11 & 1547013 & all1304* & upstream & bicarbonate transporter & - & 1546894 & GTGCATTTGCAATAGTTATTAT \\
\hline 35 & 31,96 & 1620674 & all1365 & downstream & cytochrome CytM & + & 1620645 & CGTAATAAATTTTAATCATCAT \\
\hline 37 & 63,26 & 1785455 & alr1524* & upstream & $\mathrm{RbcL}$ & + & 1785446 & ACTTATGCCATTTCTTGATATA \\
\hline 38 & 204,06 & 1843221 & alr1576 & upstream far & dehydrogenase subunit & - & 1843218 & AGTAATAACTGCTACTTATTAC \\
\hline 61 & 29,78 & 3499605 & alr2873 & internal 3' end & possible glycerate kinase & - & 1843218 & CAAAATTAAACTGTCTAATTTC \\
\hline 86 & 170,25 & 4499861 & alr3727 & upstream & photosystem II protein D1 (psbAII) & + & 4499883 & GTATATATATTTTAGTAATATT \\
\hline 91 & 155,06 & 4693128 & all3891* & upstream & flavoprotein (flv1A) & + & 4693099 & ATTTATAAGTTTTACTTAAGCT \\
\hline 98 & 166,48 & 4993006 & all4148 & upstream & ferredoxin I & - & 4993375 & AACCATAAATTTTTCTAATAAC \\
\hline 99 & 61,47 & 4999503 & alr4156* & upstream & NADH dehydrogenase subunit 5 ; NdhF & + & 4999503 & AAAGATAAATTTGCCTTATTTA \\
\hline 108 & 163,25 & 5332512 & all $4446^{*}$ & upstream & flavoprotein (flv4) & - & 5332500 & AATAATAAATTTTACTAATAAA \\
\hline 112 & 233,71 & 5489698 & alr4592* & upstream & photosystem II protein D1 (psbAIII) & + & 5489979 & CTATATAGTTTTTACTCATATT \\
\hline 121 & 51,04 & 6151146 & alr5154 & upstream & photosystem I core protein A1 & + & 6151133 & GGACATAAGTTTTACGAATTGT \\
\hline
\end{tabular}

*Genes whose expression has been studied by qRT-PCR

IFunctions are as specified in cyanobase (http://genome.microbedb.jp/cyanobase/Anabaena).

BR: binding region, NLQ: - -logQvalue, LOC: chromosome location of the midpoint of the binding region, ST: DNA strand, START: chromosome location of the 5' end of the putative binding sequence of All3953 (SEQ). 


\section{Page 51 of 54}

Picossi et al., Fig. 1

A

\begin{tabular}{|l|c|c|}
\hline \multirow{2}{*}{$\begin{array}{l}\text { Growth } \\
\text { conditions }\end{array}$} & \multicolumn{2}{c|}{$\mu$ (day $^{-1}$ ) } \\
\cline { 2 - 3 } & CSS77 & CSS74 \\
\hline HL HC & $0.892 \pm 0.072$ & $0.287 \pm 0.074$ \\
\hline HL LC & $0.602 \pm 0.078$ & $0.406 \pm 0.030$ \\
\hline LL HC & $0.620 \pm 0.061$ & $0.454 \pm 0.027$ \\
\hline LL LC & $0.607 \pm 0.051$ & $0.523 \pm 0.028$ \\
\hline
\end{tabular}

B

$\operatorname{CSS77} \quad \operatorname{cSS} 74 \quad \operatorname{css} 77 \quad \operatorname{css} 74$

$\mathrm{HL}$

$\mathrm{HC}$

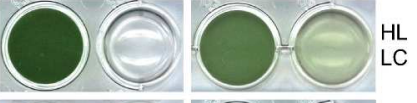

LL

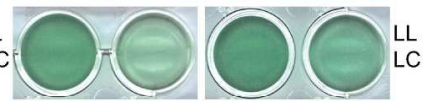

Figure 1

$262 \times 350 \mathrm{~mm}(300 \times 300$ DPI $)$ 
Picossi et al., Fig. 2

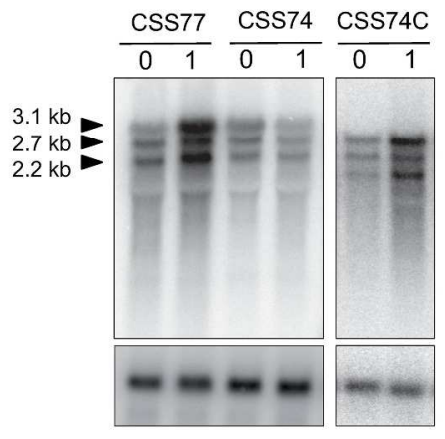

Figure 2

$262 \times 350 \mathrm{~mm}(300 \times 300$ DPI $)$ 
Picossi et al., Fig. 3

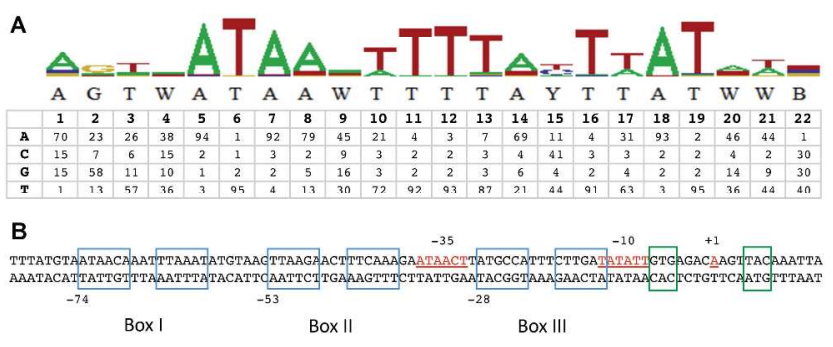

Figure 3

297x420mm (300 x 300 DPI) 

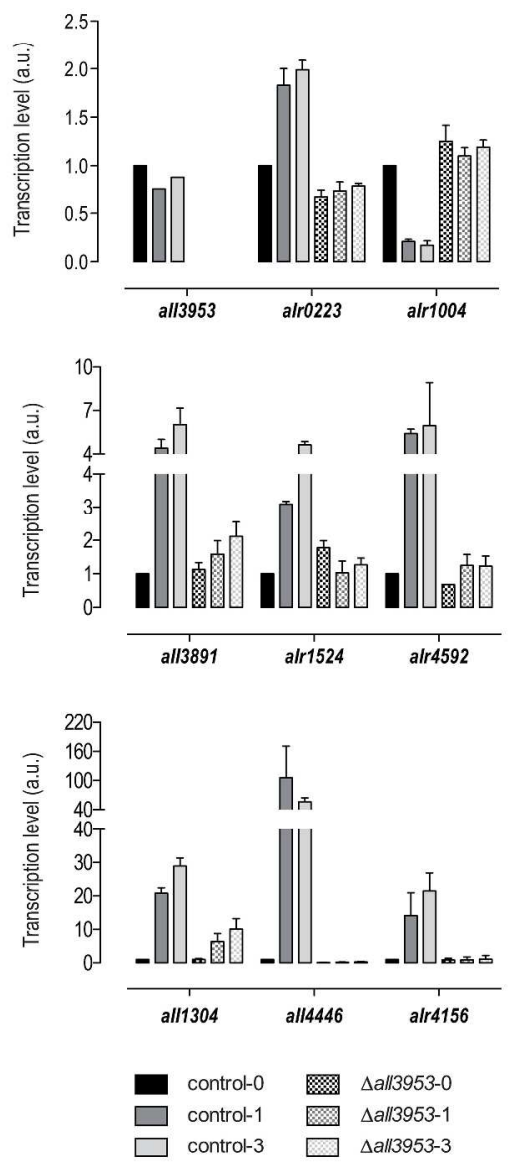

Figure 4 $297 \times 420 \mathrm{~mm}(300 \times 300$ DPI) 